\title{
Initial Series of Ruthenium Adsorption Optimization Studies
}

Nuclear Technology

Research and Development

$$
\begin{array}{r}
\text { Prepared for } \\
\text { U.S. Department of Energy } \\
\text { Material Recovery and Waste Form } \\
\text { Development Campaign } \\
\text { B. B. Spencer and S. H. Bruffey } \\
\text { Oak Ridge National Laboratory } \\
31 \text { August } 2018 \\
\text { NTRD-MRWFD-2018-000197 } \\
\text { ORNL/SPR-2018/913 }
\end{array}
$$




\section{DISCLAIMER}

This information was prepared as an account of work sponsored by an agency of the U.S. Government. Neither the U.S. Government nor any agency thereof, nor any of their employees, makes any warranty, expressed or implied, or assumes any legal liability or responsibility for the accuracy, completeness, or usefulness, of any information, apparatus, product, or process disclosed, or represents that its use would not infringe privately owned rights. References herein to any specific commercial product, process, or service by trade name, trade mark, manufacturer, or otherwise, does not necessarily constitute or imply its endorsement, recommendation, or favoring by the U.S. Government or any agency thereof. The views and opinions of authors expressed herein do not necessarily state or reflect those of the U.S. Government or any agency thereof. 


\section{SUMMARY}

The processing of used nuclear fuel releases volatile and semivolatile radionuclides into the off-gas streams associated with the various processing steps. Ongoing efforts to develop methods to control the release of gaseous radionuclides to the environment have identified ruthenium (specifically ${ }^{106} \mathrm{Ru}$ ) as one of the semivolatile nuclides requiring a high degree of abatement. The tritium pretreatment process will release a fraction of the ruthenium as volatile ruthenium tetroxide $\left(\mathrm{RuO}_{4}\right)$. Tests were conducted to examine the deposition phenomena and provide preliminary information pertinent to an engineering design of a sorption bed to remove $\mathrm{RuO}_{4}$ from a gas stream (e.g., approximate length of the mass transfer zone and the loading per unit mass of sorbent).

Three methods were used to produce $\mathrm{RuO}_{4}$ for the sorption tests: (1) dry oxidation of powdered ruthenium metal, (2) dry oxidation of ruthenium dioxide $\left(\mathrm{RuO}_{2}\right)$ with molten sodium periodate $\left(\mathrm{NaIO}_{4}\right)$, and (3) oxidation of $\mathrm{RuO}_{2}$ with $\mathrm{NaIO}_{4}$ in an aqueous phase. The latter method proved the most useful for producing sufficient volatile ruthenium to deposit measurable quantities of ruthenium on the sorbents.

Adsorption media included stainless steel wire mesh (screen) to act as a thin bed sorbent and steel wool packing to act as a deep bed sorbent. Both were contained in a quartz tube column, and in several tests the screen was immediately followed by the steel wool. The column was followed by an aqueous scrubber filled with caustic solution to retain any $\mathrm{RuO}_{4}$ that passed through the column. Use of the high surface steel wool stripped the gas phase of $\mathrm{RuO}_{4}$ to such an extent that concentrations of ruthenium in a downstream caustic scrubber solution were near or below the detectable limit of ICP-MS analysis.

Initial tests showed that $\mathrm{RuO}_{4}$ deposited on a variety of heated surfaces (temperatures $>100^{\circ} \mathrm{C}$ ), including the Teflon O-rings used as spacers between the wire mesh disks, glass spacers, quartz tube, and the metallic sorbents. Deposition at room temperature was very minimal, permitting the use of Teflon tubing for unheated sections of the apparatus. Deposition became very rapid and complete at elevated temperatures (i.e., at $150^{\circ} \mathrm{C}$ or higher).

At a bed temperature of $150^{\circ} \mathrm{C}$ and carrier gas flowrate of $0.25 \mathrm{slpm}$ through a 1-in. ID quartz tube, penetration of the $\mathrm{RuO}_{4}$ into the bed varied strongly with the packing density of the steel wool, ranging from $1.5 \mathrm{in}$. to $6 \mathrm{in}$. Increasing the bed temperature to $250^{\circ} \mathrm{C}$ decreased the penetration into the bed to under $0.7 \mathrm{in}$. The specific loading per unit of surface area $\left(\mathrm{g} / \mathrm{cm}^{2}\right)$ was similar for both the screens and steel wool.

In one test an attempt was made to load the sorbents to saturation. This was done by loading the bed with a specific amount of ruthenium, visually observing the depth of deposits on the bed and repeating the sequence four times. The depth of penetration did not change, indicating that deposition only required a heated surface, including a surface already covered with (presumably) $\mathrm{RuO}_{2}$. The implication is that the sorbent is actually just a deposition surface, that it does not saturate at the loadings experienced in these tests, and that if this mode of deposition remains consistent with increased loading, the $\mathrm{RuO}_{2}$ layer could become sufficiently thick to plug a column if it were placed in service for too long a time.

Analysis of the scrubber solutions permitted an estimate of the amount of ruthenium passing the sorbent beds. Comparing this amount to the amount of volatile ruthenium transferred to the sorbent beds lead to estimated decontamination factors in excess of $10^{6}$ for sorbent beds composed of steel wool. 
This page is intentionally left blank. 


\section{CONTENTS}

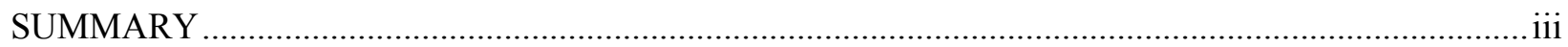

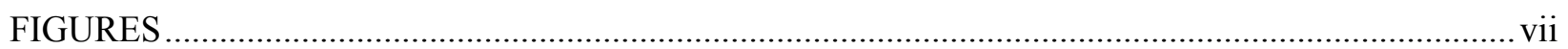

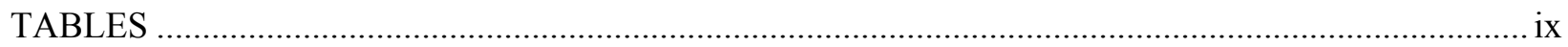

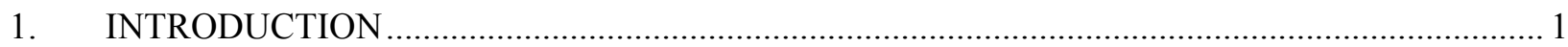

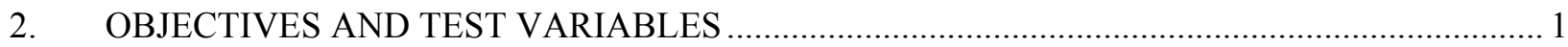

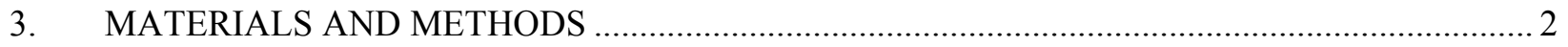

3.1 Test Apparatus and $\mathrm{RuO}_{4}$ Preparation Methods …....................................................... 2

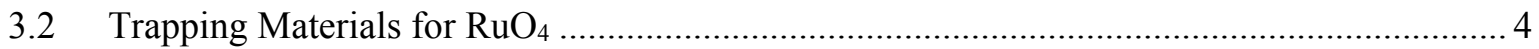

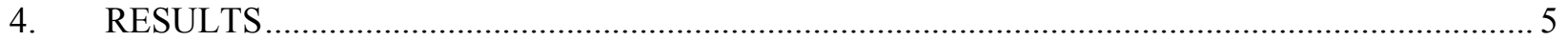

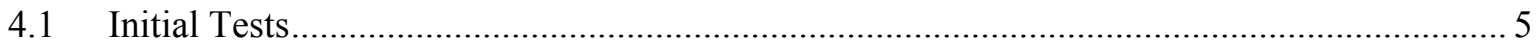

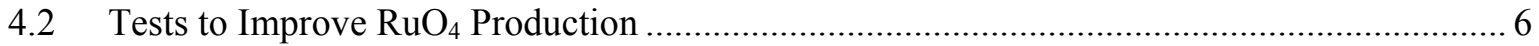

4.3 Capacity and Mass Transfer Zone in Metallic Getters....................................................... 10

4.4 Estimated Decontamination Factors ............................................................................... 25

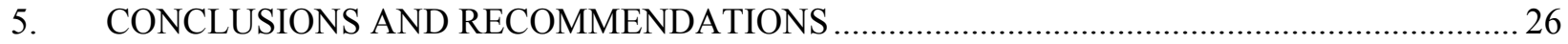

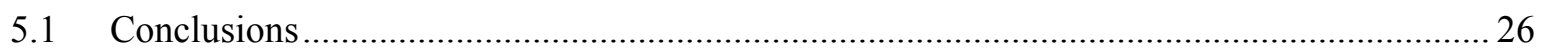

5.2 Implications for Ruthenium Capture Systems and Recommendations ................................ 27

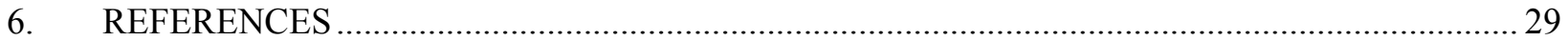


This page is intentionally left blank. 


\section{FIGURES}

Figure 1. Configuration of test system using vertical sorbent column and producing $\mathrm{RuO}_{4}$ by $\mathrm{O}_{2}$ oxidization of Ru metal.

Figure 2. Configuration of test system using a horizontal sorbent column and producing $\mathrm{RuO}_{4}$ by either $\mathrm{O}_{2}$ oxidization of $\mathrm{Ru}$ metal or reaction of dry $\mathrm{RuO}_{2}$ with $\mathrm{NaIO}_{4}$. 3

Figure 3. Test system configuration using $\mathrm{NaIO}_{4}$ oxidation of $\mathrm{RuO}_{2}$ in water and horizontal sorbent bed.

Figure 4. Color changes in aqueous solution of $\mathrm{NaIO}_{4}$ and $\mathrm{RuO}_{2}$; as volatile $\mathrm{RuO}_{4}$ is stripped from the liquid it ultimately becomes water clear.

Figure 5. Screens and Teflon spacers recovered from Run 3 column.............................................. 6

Figure 6. Quartz spacer, Teflon O-rings, and stainless steel mesh screen used in Run 8....................... 7

Figure 7. Coating on inside of Run 9's quartz tube arising from volatile produced by reactions of dry $\mathrm{RuO}_{2}-\mathrm{NaIO}_{4}$.

Figure 8. Coating on the inside of Run 9's quartz tube, which thickened and flaked when volatiles from aqueous $\mathrm{NaIO}_{4}-\mathrm{RuO}_{2}$ reaction were added in a second deposition.

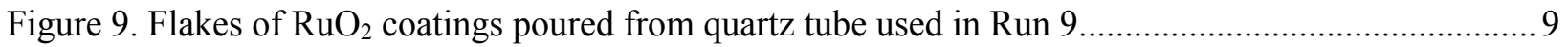

Figure 10. White Teflon O-ring (left), which was coated with $\mathrm{RuO}_{2}$ during Run 9 (right)...................... 10

Figure 11. Initial appearance of screens and steel wool packing in column (top) and appearance after deposition of ruthenium (bottom) in Run 10.

Figure 12. Appearance of column with screens and steel wool packing in Run 11: Initial condition before deposition (top) and cumulative condition after each of five separate depositions (from top to bottom).

Figure 13. Appearance of quartz tube used in Run 11 after the screens and wool were removed.

Figure 14. Steel wool section RO-11-01w removed from Run 11 quartz column. Note the glossy flake-like deposits adhered to the steel wool, which were evidently pulled from the quartz surface.

Figure 15. Screens removed from the Run 11 column showing decrease in blackening caused by deposition.

Figure 16. Photomicrograph of polished section of screen RO-11-01 from Run 11. 18

Figure 17. SEM image of screen RO-11-01 in Run 11.

Figure 18. Energy dispersive spectroscopy of screen RO-11-01 from Run 11.

Figure 19. Initial appearance of screens and steel wool packing in column (top) and appearance after deposition of ruthenium (bottom) in Run 12.

Figure 20. Post-Run 12 screens recovered from column. 21

Figure 21. First three sections of steel wool removed from column at end of Run 12.

Figure 22. Specific ruthenium loading as a function of cumulative mass of steel wool in the bed. Points are placed at the mid-point of the mass of each wool section.

Figure 23. Specific ruthenium loading on mesh screens as a function of the cumulative mass of steel wool preceding the mesh. 
Figure 24. Comparison of specific ruthenium loading on the screen mesh and the steel wool as a function of cumulative mass of wool in the bed....

Figure 25. First screen (RO-13-01) and steel wool section (RO-13-01w) recovered following Run 13.

Figure 26. SEM image of screen RO-13-01 from Run 13. The area where the coating is chipped from the surface reveals the depth of the $\mathrm{RuO}_{2}$ deposit. 


\section{TABLES}

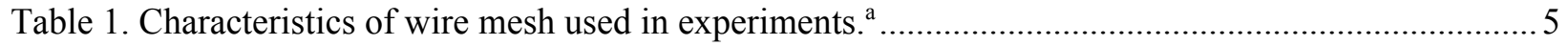

Table 2. Properties of wire mesh and amount of $\mathrm{RuO}_{2}$ deposited in $\mathrm{Run} 9 .^{\mathrm{a}}$.......................................... 10

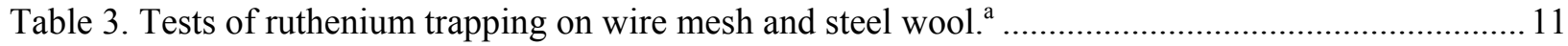

Table 4. Measured mass of sorbent materials in Run 10 and calculated ruthenium loadings................... 13

Table 5. Measured mass of sorbent materials in Run 11 and calculated ruthenium loadings.................... 13

Table 6. Measured mass of sorbent materials in Run 12 and calculated ruthenium loadings.................... 14

Table 7. Measured mass of sorbent materials in Run 13 and calculated ruthenium loadings.................... 14

Table 8. Analysis of scrubber solution for selected experiments and calculated mass of ruthenium

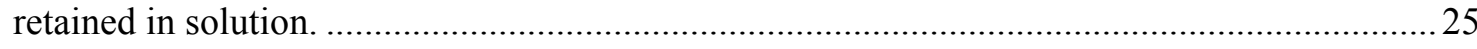

Table 9. Estimated DFs describing removal of removal of ruthenium from a gas. ..................................26 
This page is intentionally left blank. 


\section{INITIAL SERIES OF RUTHENIUM ADSORPTION OPTIMIZATION STUDIES}

\section{INTRODUCTION}

Ruthenium is an element that can form volatile species in either the tritium pretreatment or fuel dissolution processes of a used nuclear fuel reprocessing facility. It is designated as a semivolatile element because only a fraction of the metal volatilizes as the quasistable ruthenium tetroxide, $\mathrm{RuO}_{4}$. Because ${ }^{106} \mathrm{Ru}$ has been identified as one of the semivolatile nuclides requiring a high degree of abatement, methods to remove it from off-gas streams have been identified (Jubin et al. 2014). A more detailed summary of the background and rational for capture of ruthenium is available in a previous literature review (Jubin et al. 2017).

In a recent experimental study (Spencer et al. 2018), silica gel at $40^{\circ} \mathrm{C}$ and carbon steel wool at $150^{\circ} \mathrm{C}$ were tested as sorbents. The $\mathrm{RuO}_{4}$ was produced by oxidizing a small quantity of ruthenium metal at temperatures between $500^{\circ} \mathrm{C}$ and $700^{\circ} \mathrm{C}$, with the gas stream being rapidly cooled as it flowed through bare piping to the temperature-controlled sorbent bed. Based on measurements of the mass of the beginning ruthenium metal and the residual (presumed) $\mathrm{RuO}_{2}$, the amount of $\mathrm{RuO}_{4}$ produced was in the single digits to tens of milligrams range. Visual observations of the color of the silica gel indicated that it adsorbed $\mathrm{RuO}_{4}$ but slowly released it during storage at room temperature. Color changes in the steel wool indicated that the ruthenium was sorbed, with no release after extended storage. In each case, caustic scrubbing of the sorbent bed effluent gas and analysis of the scrubber solution was used to ascertain the amount of ruthenium, if any, that passed the sorbent bed. Analytical methods were used to estimate the quantity of ruthenium in the scrubber solutions and on the steel wool. The observed release of ruthenium from the silica sorbent during these tests informed the decision to limit further testing to metal sorbent media only.

Ultimately there will be a need to design a sorbent system capable of removing ruthenium to reduce effluent concentrations to, or below, regulatory limits. Data are lacking to provide a basis for estimating the length of the mass transfer zone or the loading per unit mass of sorbent.

\section{OBJECTIVES AND TEST VARIABLES}

Present analyses of an integrated off-gas system for head-end operations, including the off-gas streams from the tritium pretreatment and fuel dissolution processes, indicate that engineering parameters to enable an effective ruthenium sorbent bed design are lacking (Jubin et al. 2017). The objectives of the present work are to complete an initial series of ruthenium adsorption studies and provide recommended changes to the assumptions used in the analysis of an integrated off-gas system. It is expected that the data will also be applicable to additional systems such as the melter off-gas system and the broader range of system processing alternatives.

Two important parameters required for designing sorbent beds are the length of the mass transfer zone and the sorption capacity of the sorbent. In traditional sorption processes using a given sorbent, these parameters depend primarily on porosity of the sorbent, available surface area in the sorbent, superficial velocity of the gas stream, concentration of the sorbate in the gas stream, and sorption temperature. A limited number of test conditions, primarily sorbent temperature and sorbent surface area, were selected to address the impacts of operating conditions on the mass transfer zone and sorption capacity of metal media for $\mathrm{RuO}_{4}$. 


\section{MATERIALS AND METHODS}

\subsection{Test Apparatus and $\mathrm{RuO}_{4}$ Preparation Methods}

The experimental apparatus consisted of a gas supply, mass flow controller to feed the gas, means to produce $\mathrm{RuO}_{4}$ that would enter the flowing gas stream, furnace to heat the sorbent material bed, and caustic scrubber to remove and collect any remaining $\mathrm{RuO}_{4}$ from the gas stream leaving the sorbent bed. Three different methods to produce $\mathrm{RuO}_{4}$ were used, which necessitated minor variations in the test equipment configuration.

The first method to produce $\mathrm{RuO}_{4}$ was previously described by Spencer et al. (2018) and is shown in Figures 1 and 2. In summary, the method was designed to produce a dry gas stream containing $\mathrm{RuO}_{4}$ vapor. Ruthenium metal powder was sieved to obtain particles between $38 \mu \mathrm{m}$ and $105 \mu \mathrm{m}$ in diameter. The powder was placed in a quartz boat, which in turn was placed in a 1-in. inner diameter (ID) quartz tube housed in a temperature-controlled furnace. The powder was heated to temperatures ranging from $500^{\circ} \mathrm{C}$ to $700^{\circ} \mathrm{C}$ while flowing pure oxygen over the powder surface. The gas stream containing $\mathrm{RuO}_{4}$ then flowed through a short section of bare tubing to cool the gas stream, which then flowed into either a sorbent bed contained in a 1 -in. ID glass column wrapped in thermostatically controlled heat tape $\left(50^{\circ} \mathrm{C}\right)$ or a sorbent bed contained in a 1-in. ID quartz tube housed in a temperature-controlled oven $\left(150^{\circ} \mathrm{C}\right)$. The gas stream exhausted from the sorbent bed was then routed to a caustic scrubber to collect any residual $\mathrm{RuO}_{4}$. Analysis of the scrubber solution or changes in the mass of the ruthenium metal powder provided a measure of the amount of ruthenium that passed through the sorbent bed.

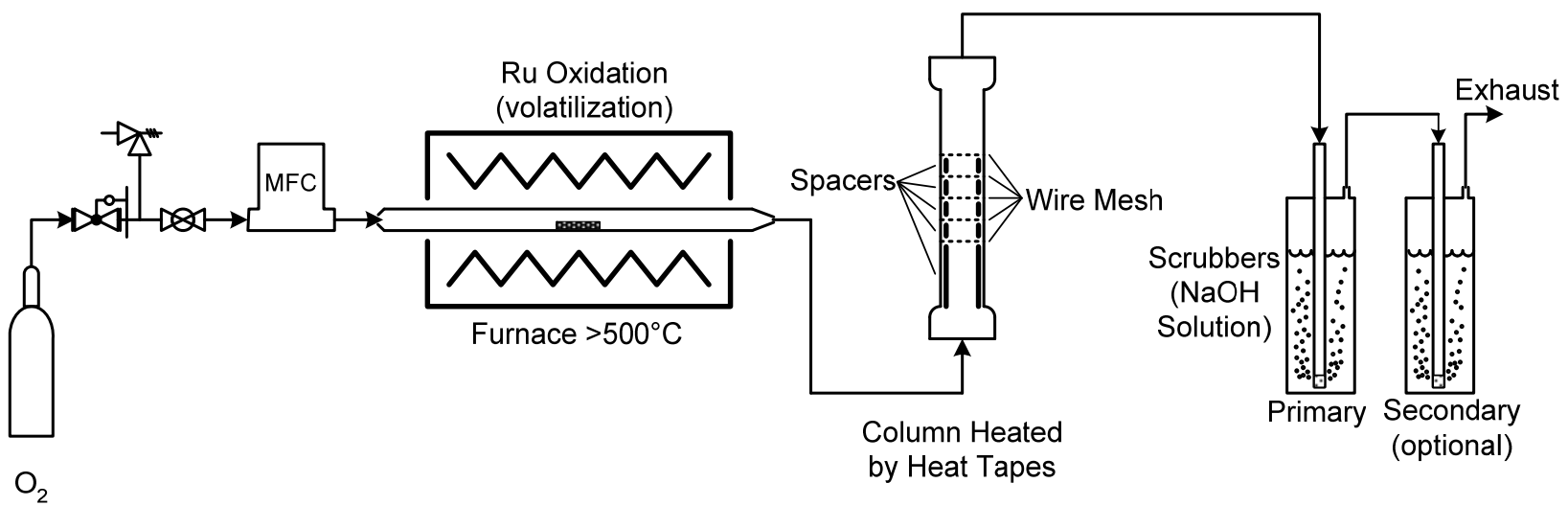

Figure 1. Configuration of test system using vertical sorbent column and producing $\mathrm{RuO}_{4}$ by $\mathrm{O}_{2}$ oxidization of Ru metal.

The second method used a configuration similar to that shown in Figure 2 but changes in the reagents were made. Reactions of sodium periodate $\left(\mathrm{NaIO}_{4}\right)$ with ruthenium dioxide $\left(\mathrm{RuO}_{2}\right)$ to produce $\mathrm{RuO}_{4}$ in aqueous solution have been reported in the literature (Lee et al. 1972). Whether the reagents are in solution or are dry, the reactions are strongly favored over a wide range of temperatures, according to thermochemical calculations. Sodium periodate (anhydrous from Sigma Aldrich) was placed in the reagent boat and $\mathrm{RuO}_{2}$ (as $\mathrm{RuO}_{2} \cdot \mathrm{xH}_{2} \mathrm{O}, \mathrm{Ru}$ content $\geq 54 \mathrm{wt} \%$, from Alfa-Aesar) was sprinkled over the top of the $\mathrm{NaIO}_{4}$. The oxygen gas was replaced with argon gas because there was concern that the reaction could be highly energetic. A test was completed with this arrangement using no sorbent and no heating of the 1-in. ID quartz tube, and the caustic scrubbers were used to determine the amount of $\mathrm{RuO}_{2}$ that could be converted to $\mathrm{RuO}_{4}$ vapor and pass through the test apparatus. The generating oven temperature was increased incrementally up to $300^{\circ} \mathrm{C}$, the melting temperature of $\mathrm{NaIO}_{4}$. No color change, indicating the presence of 
$\mathrm{RuO}_{4}$, was observed in the scrubber until the oven reached $300^{\circ} \mathrm{C}$. A rapid color change in the scrubber indicated a rapid evolution of $\mathrm{RuO}_{4}$, but the evolution appeared to be short lived. Post-test examination revealed splattering of the material from the boat, indicating either a rapid reaction to produce gaseous $\mathrm{RuO}_{4}$, evaporation of any waters of hydration on the $\mathrm{RuO}_{2}$, or both. Only one test was completed with this arrangement.

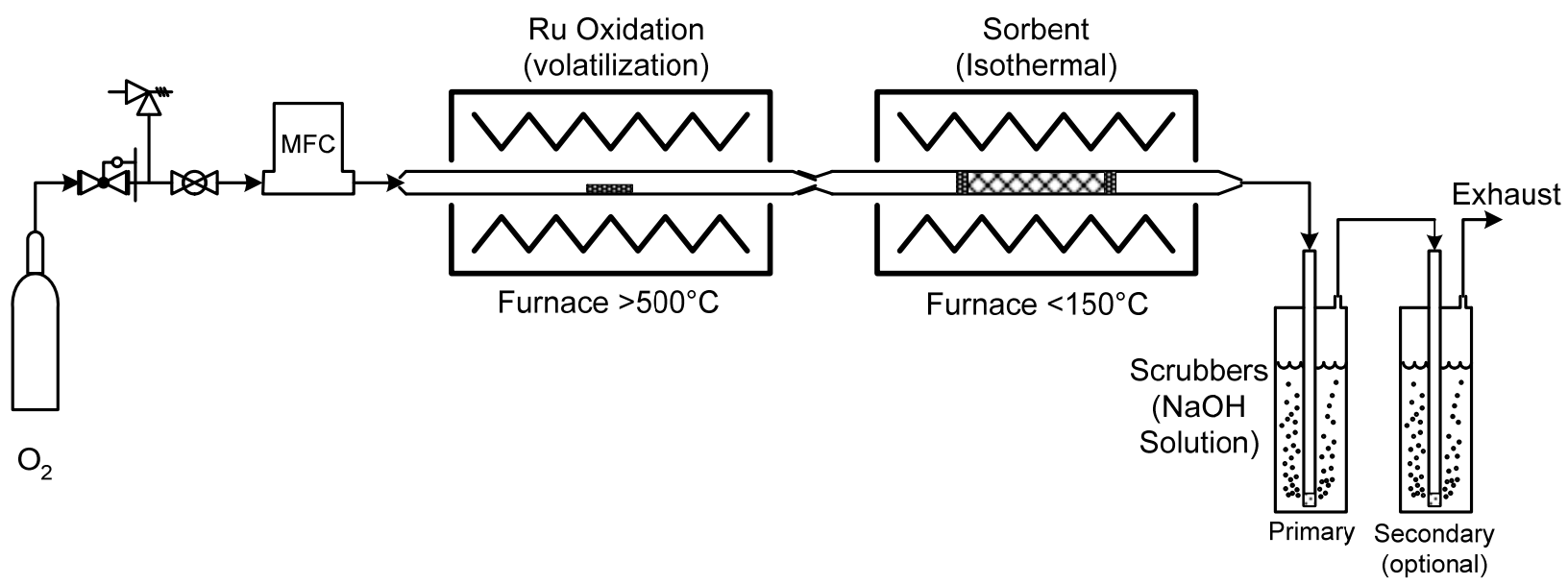

Figure 2. Configuration of test system using a horizontal sorbent column and producing $\mathrm{RuO}_{4}$ by either $\mathrm{O}_{2}$ oxidization of Ru metal or reaction of dry $\mathrm{RuO}_{2}$ with $\mathrm{NaIO}_{4}$.

Neither the first or second method of producing $\mathrm{RuO}_{4}$ resulted in $\mathrm{RuO}_{4}$ quantities practical for completing the experimental objectives. Scrubber solutions displayed the correct color (yellow to orange) to indicate the presence of $\mathrm{RuO}_{4}$, but the mass of ruthenium transported from the reaction boat and the mass of black deposits of (presumably) $\mathrm{RuO}_{2}$ were too small to provide reliable values of the mass loading on the sorbents. A decision was made to try a third method based on the technique described by Lee et al. (1972). This reference indicated that a 4:1 mass ratio of $\mathrm{NaIO}_{4}: \mathrm{RuO}_{2}$ placed in water and stirred would produce $\mathrm{RuO}_{4}$, which could be extracted into carbon tetrachloride; the amount of water used was not provided. A modification of the procedure was developed in which the $\mathrm{NaIO}_{4}$ would be dissolved in water at room temperature to a concentration near the solubility limit, and the powdered $\mathrm{RuO}_{2}$ would be added while stirring. Bubbling a carrier gas stream (e.g., air or Ar) through the solution at $0.25 \mathrm{slpm}$ slowly stripped the $\mathrm{RuO}_{4}$ from solution, carrying it to the sorbent columns. It was found that $\mathrm{NaIO}_{4}: \mathrm{RuO}_{2}$ in a $6: 1$ mass ratio converted nearly all the $\mathrm{RuO}_{2}$ to a volatile form, but the method necessarily added some water vapor to the gas stream. Because heating was not necessary and gas flow rates were low, the amount of water vapor entering the gas stream was small.

Experiments were performed using a small three-neck flask to produce the $\mathrm{RuO}_{4}$, as shown in Figure 3 . The nominal quantities of reagents used for each $\mathrm{RuO}_{4}$ production run were $30-40 \mathrm{~mL} \mathrm{H}_{2} \mathrm{O}, 3 \mathrm{~g}$ of NaIO , and $0.5 \mathrm{~g}$ of $\mathrm{RuO}_{2}$. Dissolution of the $\mathrm{NaIO}_{4}$ in water at room temperature $\left(\sim 21^{\circ} \mathrm{C}\right)$ required around $10 \mathrm{~min}$, resulting in a slightly cloudy-to-water-clear solution. Transferring the charge of $\mathrm{RuO}_{2}$ into the stirred solution resulted in a brown-to-black slurry with deep green hues, with immediate evolution of a gas presumed to be $\mathrm{RuO}_{4}$. Within a few minutes the solution became a deep yellow-orange color with no visible particulate remaining. As gas continued bubbling through the solution to remove the volatile compound, the solution became a progressively lighter yellow color, ultimately becoming water clear. A sequence of color changes in the $\mathrm{RuO}_{4}$ generator is shown in Figure 4. The gas leaving the generator flowed to a sorbent bed contained in a 1-in. ID quartz tube heated to temperatures of either $150^{\circ} \mathrm{C}$ or $250^{\circ} \mathrm{C}$ in a temperature-controlled oven. 


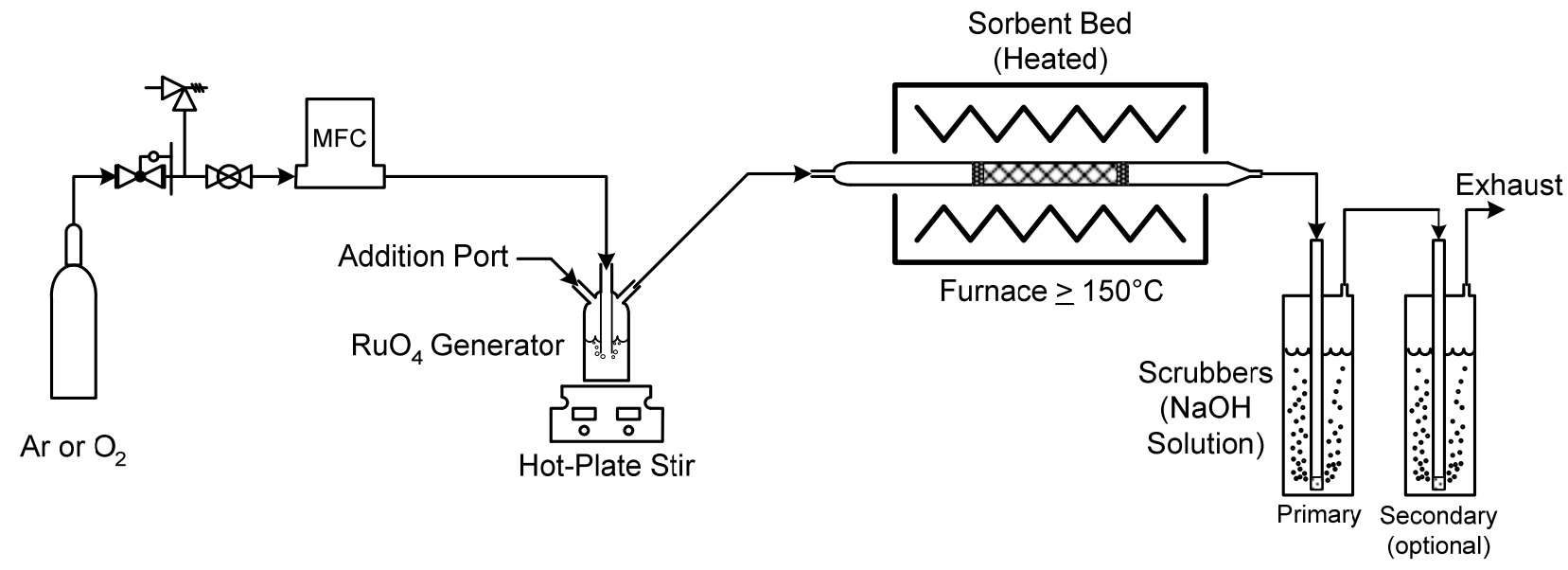

Figure 3. Test system configuration using $\mathrm{NaIO}_{4}$ oxidation of $\mathrm{RuO}_{2}$ in water and horizontal sorbent bed.
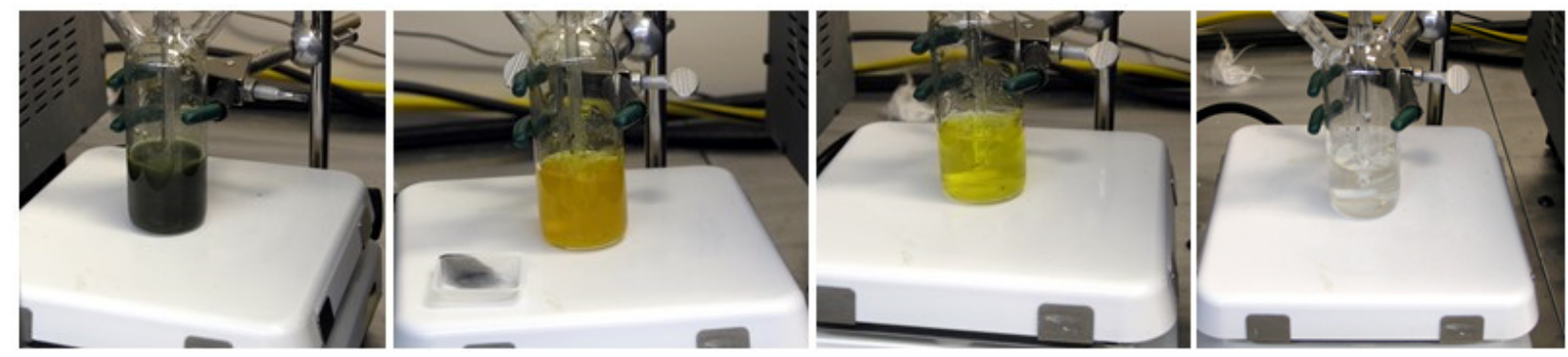

Figure 4. Color changes in aqueous solution of $\mathrm{NaIO}_{4}$ and $\mathrm{RuO}_{2}$; as volatile $\mathrm{RuO}_{4}$ is stripped from the liquid it ultimately becomes water clear.

\subsection{Trapping Materials for $\mathrm{RuO}_{4}$}

Based on prior work (Spencer et al. 2018), metallic materials were selected for the sorbent. (More appropriately, the metallic materials would be considered deposition surfaces, but the term sorbent is used to provide continuity with prior studies.) The materials included wire cloth (or screen) and steel wool.

Wire cloth made with 304 stainless steel was purchased from McMaster-Carr. Material in two mesh sizes was obtained, $40 \times 40$ and $100 \times 100$, having characteristics as shown in Table 2 . Circular disks of material were cut using precision laser cutting, which left behind no slag, to fit the inside diameter (e.g., 1-in.) of the sorbent column or tube. The density of 304 stainless steel is $8.02 \mathrm{~g} / \mathrm{cm}^{3}$ (Perry and Chilton 1973).

Grade 0000 carbon steel wool manufactured by Rhodes American was obtained from McMaster-Carr. Standard specifications for grade 0000 steel wool (Palmer Engineering 2018) is a mean fiber width ranging from 0.0006 in. to 0.001 in. The as-received fibrous material was rolled and folded into pads. It was unrolled and cut into strips to prepare sections of sorbent bed. The density of carbon steel is $7.86 \mathrm{~g} / \mathrm{cm}^{3}$ (Perry and Chilton 1973). 
Table 1. Characteristics of wire mesh used in experiments. ${ }^{\mathrm{a}}$

\begin{tabular}{|l|c|c|c|}
\hline \multicolumn{1}{|c|}{ Mesh size } & $\begin{array}{c}\text { Wire dia. } \\
\text { (in.) }\end{array}$ & $\begin{array}{c}\text { Opening size } \\
\text { (in.) }\end{array}$ & $\begin{array}{c}\text { Open area } \\
(\%)\end{array}$ \\
\hline $40 \times 40$ & 0.010 & 0.015 & 36 \\
\hline $100 \times 100$ & 0.0045 & 0.006 & 30 \\
\hline
\end{tabular}

${ }^{a}$ Characteristics from McMaster-Carr catalog, 2018.

Solution used in the liquid scrubbers was $1.000 M( \pm 0.005 M)$ sodium hydroxide $(\mathrm{NaOH})$ obtained from Fisher Chemical. Reagent-grade sodium hypochlorite ( $\mathrm{NaOCl}$, Sigma Aldrich) solution at a concentration between 4.00 and $4.99 \mathrm{wt} \%$ was used as an additive to stabilize $\mathrm{RuO}_{4}$ in solution. The volumetric ratio of $\mathrm{NaOH}$ solution to $\mathrm{NaOCl}$ solution used in the scrubbers was $\sim 10: 1$.

\section{RESULTS}

\subsection{Initial Tests}

Three experiments were performed using $100 \times 100$ stainless steel mesh (screens) for deposition surfaces. In these tests, the $\mathrm{RuO}_{4}$ was prepared by flowing oxygen $(0.5 \mathrm{slpm})$ over powdered ruthenium metal ( $0.8271 \mathrm{~g}$ with particles $35-105 \mu \mathrm{m}$ obtained by sieving) contained in a quartz boat placed in a quartz tube heated to temperatures up to $700^{\circ} \mathrm{C}$. The test configuration is illustrated in Figure 1. In the first test (Run 1), the screens in the glass column were separated by Teflon spacers cut from thin-walled tubing; the tubing outer diameter (OD) was very slightly less than the glass column ID, and the diameter of the screen disks were the same as the column ID. The column containing the screens was maintained at $50^{\circ} \mathrm{C}$. After running the for $3.4 \mathrm{~h}$, the experiment was shut down, and the components allowed to cool overnight. When the screens were examined, it was noted that their appearance had changed from the initial metal grey to black. The average beginning screen mass was $0.3011 \mathrm{~g}$, and weight gain on each screen was less than $0.0005 \mathrm{~g}$ (i.e., $<0.2 \%$ weight gain). It was also observed that black deposits (presumed to be a ruthenium oxide) had accumulated on the cut edges of the spacers. Because the spacers had been cut on a band saw, the cut edges were roughened, evidently leading to increased surface area and micro-crevices where deposition could occur. The smooth surfaces of the Teflon spacers revealed no such deposits. The spacers had not been previously weighed, so the amount of material deposited on them could not be determined. The $1.0 \mathrm{M}$ solution $(500 \mathrm{~mL})$ in the scrubber downstream of the sorbent column had become a light-yellow color, indicating that some $\mathrm{RuO}_{4}$ had passed through the column.

In a second test (Run 2), quartz wool was used as spacer material to separate the stainless steel screens, with the assumption that the quartz would act as an insignificant sorbing surface. The experimental setup was similar to Run 1, except the column containing the screens was maintained at $150^{\circ} \mathrm{C}$ and the $\mathrm{RuO}_{4}$ generator was loaded with $0.7927 \mathrm{~g}$ of powdered ruthenium metal. Operating time at temperature was $4.1 \mathrm{~h}$. After the sorbent column had cooled to permit retrieval of the screens, it was observed that the quartz wool supporting the first screen also acted as a deposition surface, and based on the lack of change in the color of the screens, little ruthenium reached the screens. It was also noted that some wispy black deposits had appeared on the quartz tube of the $\mathrm{RuO}_{4}$ generator, near the trailing edge of the heated section of the furnace. There was no measurable change in the mass of the screens. In addition, there was no color change in the scrubber solution, indicating that little or no ruthenium had passed the sorbent column.

In a third test (Run 3) commercially produced Teflon sleeve bearings that are very smooth on all surfaces were used as spacers between the screens. Test conditions were as in Run 2, with $0.5615 \mathrm{~g}$ of unsieved ruthenium metal powder placed in the generator boat. Operating time at temperature was $3.75 \mathrm{~h}$. Following the run, black deposits were noted on the screens at the spacer-to-screen interface, as well as on the 
spacers, see Figure 5. Screens are numbered with low numbers (e.g., RO-3-01) at the feed end of the column and sequentially increasing in the direction of gas flow. Weighing the screens before and after deposition indicated very little material $(<0.0007 \mathrm{~g})$ had deposited. Because of an uninsulated connecting tube, the gas phase cools considerably between the $\mathrm{RuO}_{4}$ generating furnace and the sorbent column. The sorbent column was heated to $150^{\circ} \mathrm{C}$ with heating tapes, but the reheating of the gas phase was likely limited by the low thermal conductivity of the spacer sleeves, which acted as insulators inside the column. The edges of the screens in direct contact with the glass were thought to be warmer because of thermal conduction through the metal, and thus the reason deposition occurred at locations within the inside diameter of the spacers (see Figure 5). No color change in the downstream scrubber solution was observed.

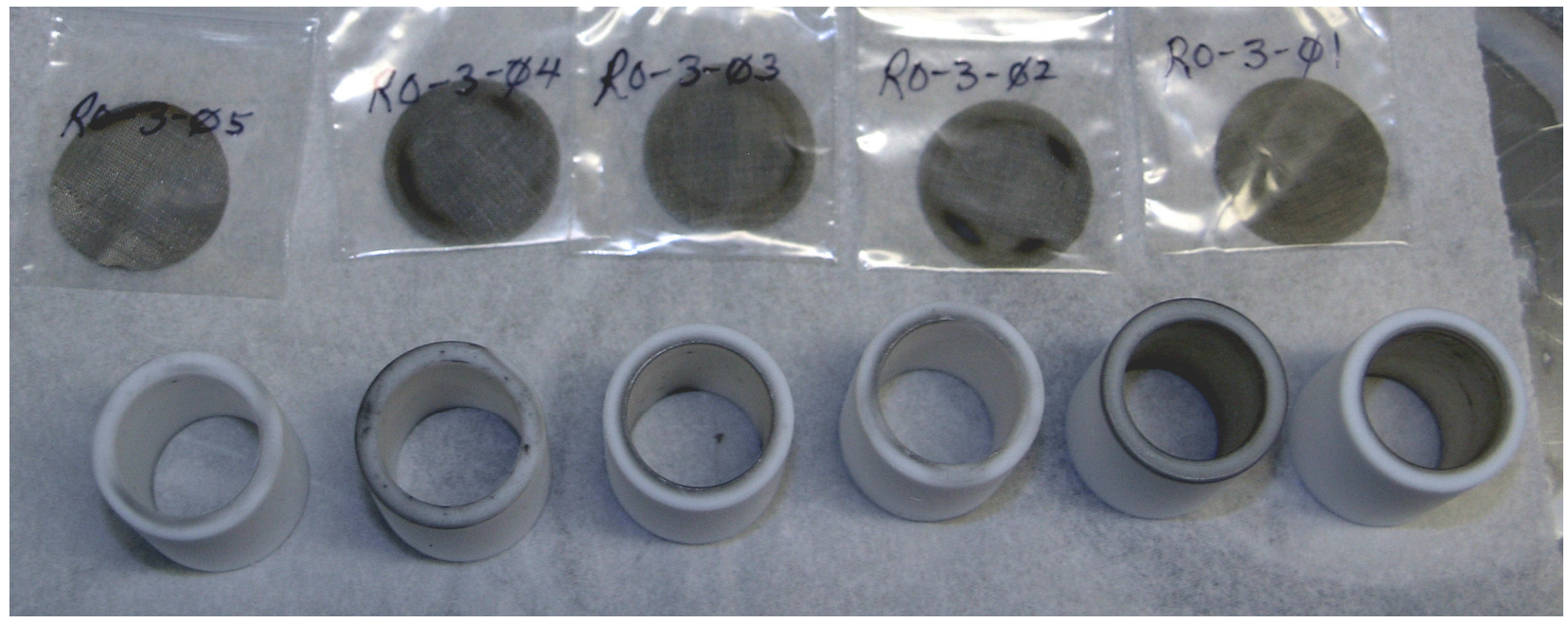

Figure 5. Screens and Teflon spacers recovered from Run 3 column.

Although reliable data on sorbent capacity could not be gleaned from these initial tests, several qualitative observations were made. After three runs it was noted that the uninsulated Teflon tubing between the $\mathrm{RuO}_{4}$-generating furnace and the sorbent column was beginning to show signs of ruthenium deposition. Material presumed to be $\mathrm{RuO}_{2}$ readily deposits on surfaces, be it metal, quartz, or Teflon, when heated to $150^{\circ} \mathrm{C}$. At lower temperatures, the $\mathrm{RuO}_{4}$ seemed to be barely reactive to solid surfaces, but it could be scrubbed from the gas phase with sodium hydroxide solution. In all tests completed to this point, it was evident that very small amounts of the ruthenium were volatilized. This is based on the amounts of oxidized (or perhaps partially oxidized) ruthenium powder remaining in the generating furnace and the observed ruthenium deposits. To address this, either much longer run times or increases in the production rate of $\mathrm{RuO}_{4}$ would be necessary to facilitate reliable quantitative analysis.

\subsection{Tests to Improve $\mathrm{RuO}_{4}$ Production}

It was strongly desired that $\mathrm{RuO}_{4}$ be produced and introduced to a dry gas stream. Oxygen obtained in compressed gas cylinders is considered "bone dry," and oxidation of ruthenium metal in pure oxygen was selected for the three tests described in the previous section. This was continued in experimental Runs 4-7, but a sorbent column was not used. Instead, the gas stream was directed to the caustic scrubber. Analysis of the scrubber solution permitted estimation of the amount of $\mathrm{RuO}_{4}$ being produced. There was also concern that light could cause decomposition of $\mathrm{RuO}_{4}$ as it traveled through the ends of the quartz tube protruding from the generating furnace, causing losses of $\mathrm{RuO}_{4}$ before it entered the connecting Teflon 
tube and glass column containing the sorbent. The four runs were done in rapid succession, using powdered ruthenium metal charges ranging from $0.5 \mathrm{~g}$ to $0.8 \mathrm{~g}$. Based on observation of color change in the caustic scrubbing solution, it was found that oxidation of ruthenium metal seemed to work best when the larger metal particles were removed by sieving and only very small particles were used $(<105 \mu \mathrm{m})$. When particles less than $35 \mu \mathrm{m}$ were not removed, the flowing gas tended to blow some particles from the boat into the generator tube. Covering the ends of the quartz generator tube with aluminum foil to block ambient light seemed to have little effect. Rather than wait for inductively coupled plasma (ICP) analysis of the scrubber solutions, another sorption test was performed using dry oxidation of ruthenium metal and experimental conditions that appeared to provide the most volatile ruthenium, which were very close to the conditions selected before the first run was performed.

To prepare for Run 8, a spacer with an open frame was fabricated from quartz (Figure 6). It was used to hold the screens near the center of the column. Screens were separated with $2 \mathrm{~mm}$ thick Teflon O-rings. This increased the residence time of the gas, allowing it to heat before contacting the screens. The test configuration shown in Figure 1 was used. A $0.6126 \mathrm{~g}$ charge of sieved ruthenium metal $(35-105 \mu \mathrm{m})$ was used in the generating oven. The oven was heated to $700^{\circ} \mathrm{C}$. The glass column holding the stainless steel screens was wrapped in heating tape and heated to $150^{\circ} \mathrm{C}$. The scrubber was charged with $400 \mathrm{~mL}$ of $1.0 \mathrm{M} \mathrm{NaOH}$ solution, and oxygen flow was $0.5 \mathrm{slpm}$. Operating time at steady-state conditions was $6 \mathrm{~h}$. Post-run inspection revealed dark deposits on the glass rods and rings of the spacer cage, O-rings, and screens. No measurable mass change in the screens resulted from this deposition. Scrubber solution became a light-yellow color, with stronger orange color in the small dead space volume of the glass frit bubbler.
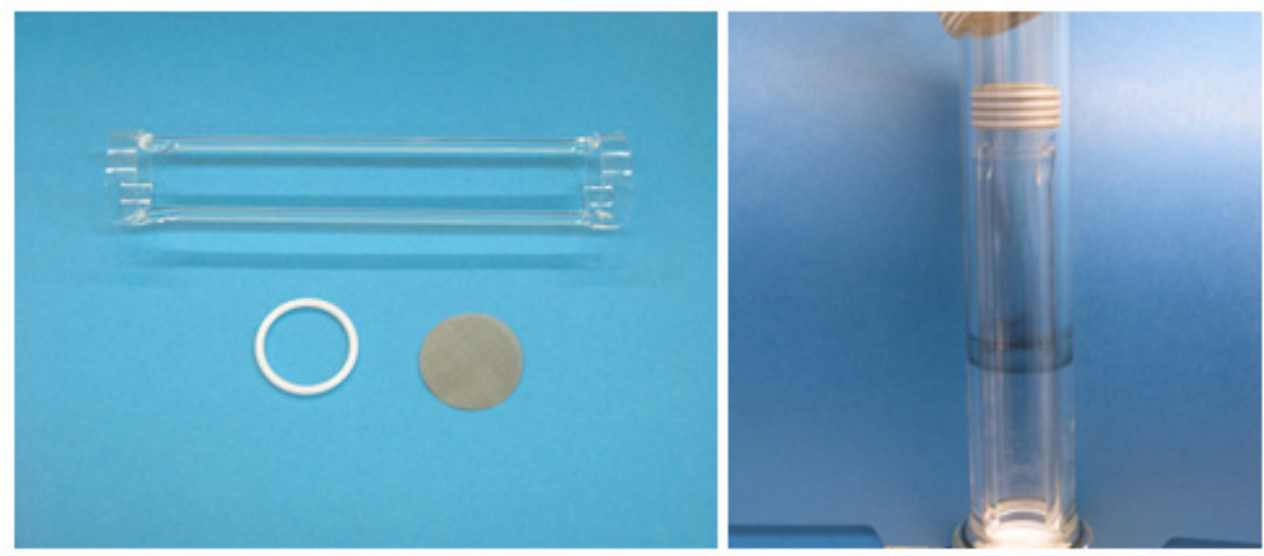

Figure 6. Quartz spacer, Teflon O-rings, and stainless steel mesh screen used in Run 8.

In an effort to produce greater quantities of $\mathrm{RuO}_{4}$, reactions between $\mathrm{RuO}_{2}$ and sodium periodate $\left(\mathrm{NaIO}_{4}\right)$ were used for Run 9. The experiment was conducted in two configurations as shown in Figures 2 and 3. The same sorbent column and scrubber solution was used for both configurations, so the ruthenium collected was the sum of the amount collected in the two operations. The sorbent column consisted of a 1in. ID quartz tube with five stainless steel $40 \times 40$ mesh screen disks of 1 -in. OD held in place by frictional fit and separated by four Teflon O-rings with a thickness of $2 \mathrm{~mm}$. This resulted in a short section of sorbent material, which was placed downstream about two-thirds of the length of the quartz tube from the leading edge of the heating zone of the furnace. The sorbent was maintained at $150^{\circ} \mathrm{C}$. To minimize tubing between the generator and the sorbent, the tubes were connected end-to-end with ground glass joints. The scrubber solution consisted of $400 \mathrm{~mL}$ of $1.0 \mathrm{M} \mathrm{NaOH}$ solution. 
In the first configuration a dry mixture of $\mathrm{RuO}_{2}(0.6044 \mathrm{~g})$ and $\mathrm{NaIO}_{4}(1.0450 \mathrm{~g})$ was placed in the quartz boat housed in a quartz tube and heated by the generating oven (as described in Section 3.1). Argon flowing at $0.5 \mathrm{slpm}$ passed over the mixture to carry the volatile $\mathrm{RuO}_{4}$ to the sorbent. The generator oven was heated incrementally to $300^{\circ} \mathrm{C}$ before any color change in the gas stream or scrubber occurred, indicating that $\mathrm{RuO}_{4}$ was generated. The gas stream exiting the generator had a purple tint, indicating some iodine generation. The scrubber solution achieved a yellow color. The production rate seemed short-lived, so the experiment was shut down after $1 \mathrm{~h}$ and allowed to cool so that the test materials could be inspected. As shown in Figure 7, black deposits were observed on the quartz sorbent column along its heated length, and the Teflon O-rings were also coated. Viewing of the screens was obscured by the coating on the quartz tube, but the screens were presumed to have deposits on them as well.

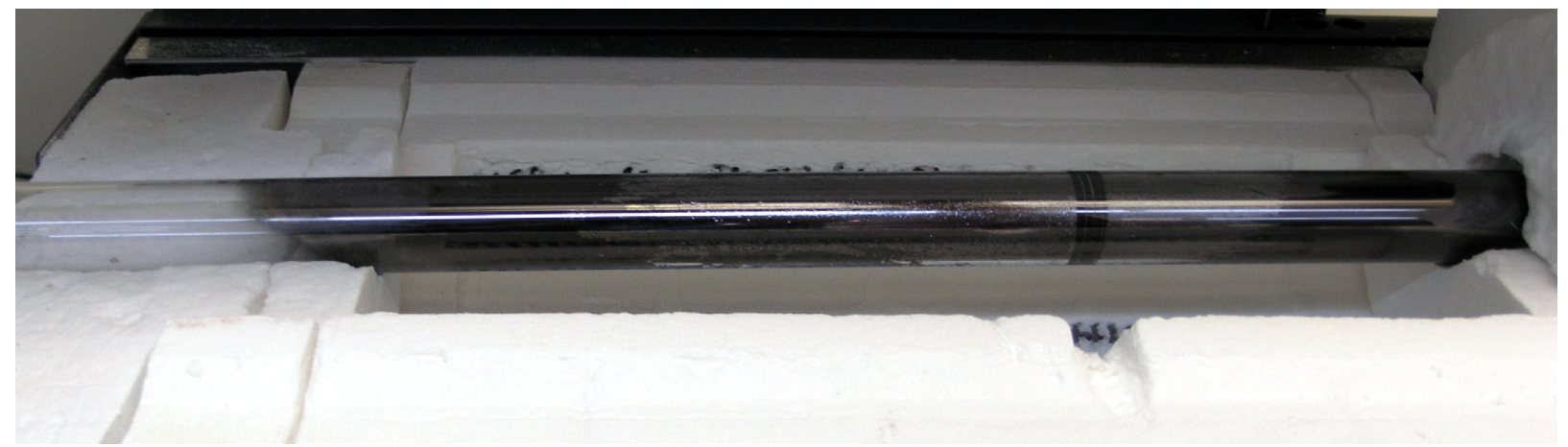

Figure 7. Coating on inside of Run 9's quartz tube arising from volatile produced by reactions of dry $\mathrm{RuO}_{2}-\mathrm{NaIO}_{4}$.

The Run 9 setup was then reconfigured as shown in Figure 3. The $\mathrm{RuO}_{4}$ was produced at room temperature in an aqueous mixture of $\mathrm{RuO}_{2}$ and $\mathrm{NaIO}_{4}$ as described in Section 3.1. Argon was fed to the system at $0.25 \mathrm{slpm}$ to carry the volatile $\mathrm{RuO}_{4}$ from the generator; the reduction in flow rate selected to prevent carrying an aerosol to the sorbent tube. The gas stream was clear and colorless. Wispy black deposits were observed on the $1 / 4$-in. Teflon tube that carried the gas from the generator to the cool section of quartz sorbent tube that extended from the front of the furnace. The sorbent tube holding the screens was heated to $150^{\circ} \mathrm{C}$, and all operating conditions were maintained for $4.4 \mathrm{~h}$, the approximate end time at which the generator solution became water clear. The downstream scrubber solution became a deep yellow color, indicating at least a portion of the $\mathrm{RuO}_{4}$ passed the column and screen surfaces. The furnace was cooled overnight. When the furnace was opened, it was observed that the deposits on the quartz tube had become darker (thickened) and that a substantial amount of the deposits had flaked-off the inside surface of the tube as shown in Figure 8. The loose material was poured into a beaker as shown in Figure 9 and saved for analysis. The reason for the flaking of the deposits is not known, but it was speculated that the deposits have a different thermal expansion coefficient than the quartz, and thermal cycling could have caused cracking and flaking of the deposits. The stainless steel screens and Teflon O-rings were removed from the quartz tube. The white O-rings had become well coated with black deposits as shown in Figure 10. 


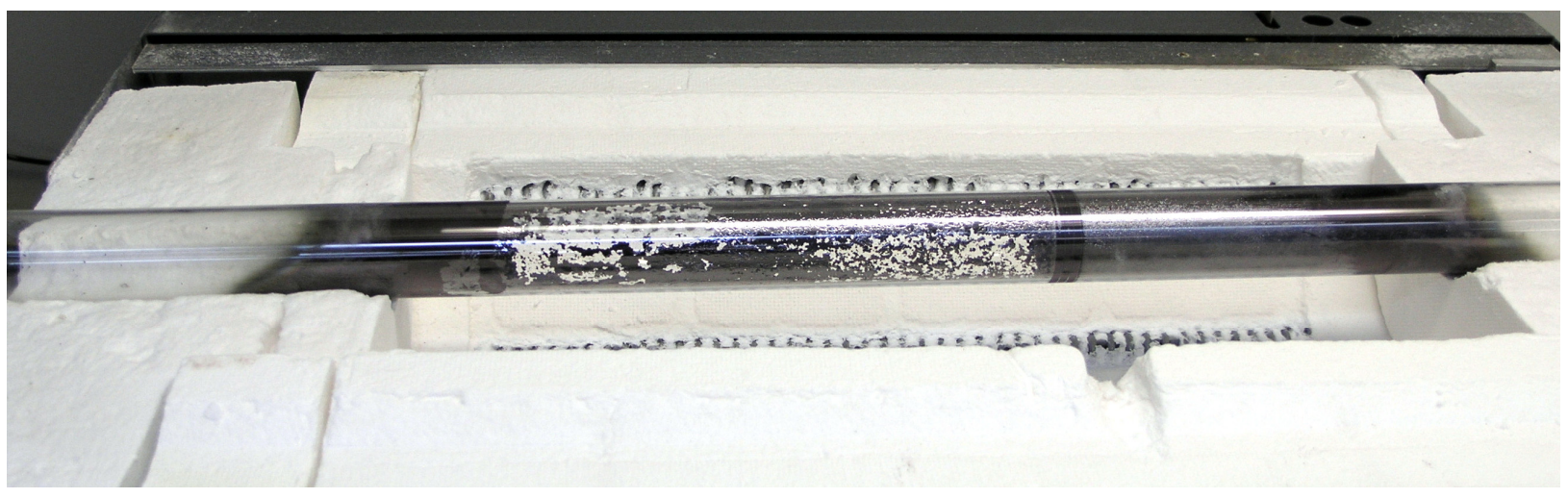

Figure 8. Coating on the inside of Run 9's quartz tube, which thickened and flaked when volatiles from aqueous $\mathrm{NaIO}_{4}-\mathrm{RuO}_{2}$ reaction were added in a second deposition.

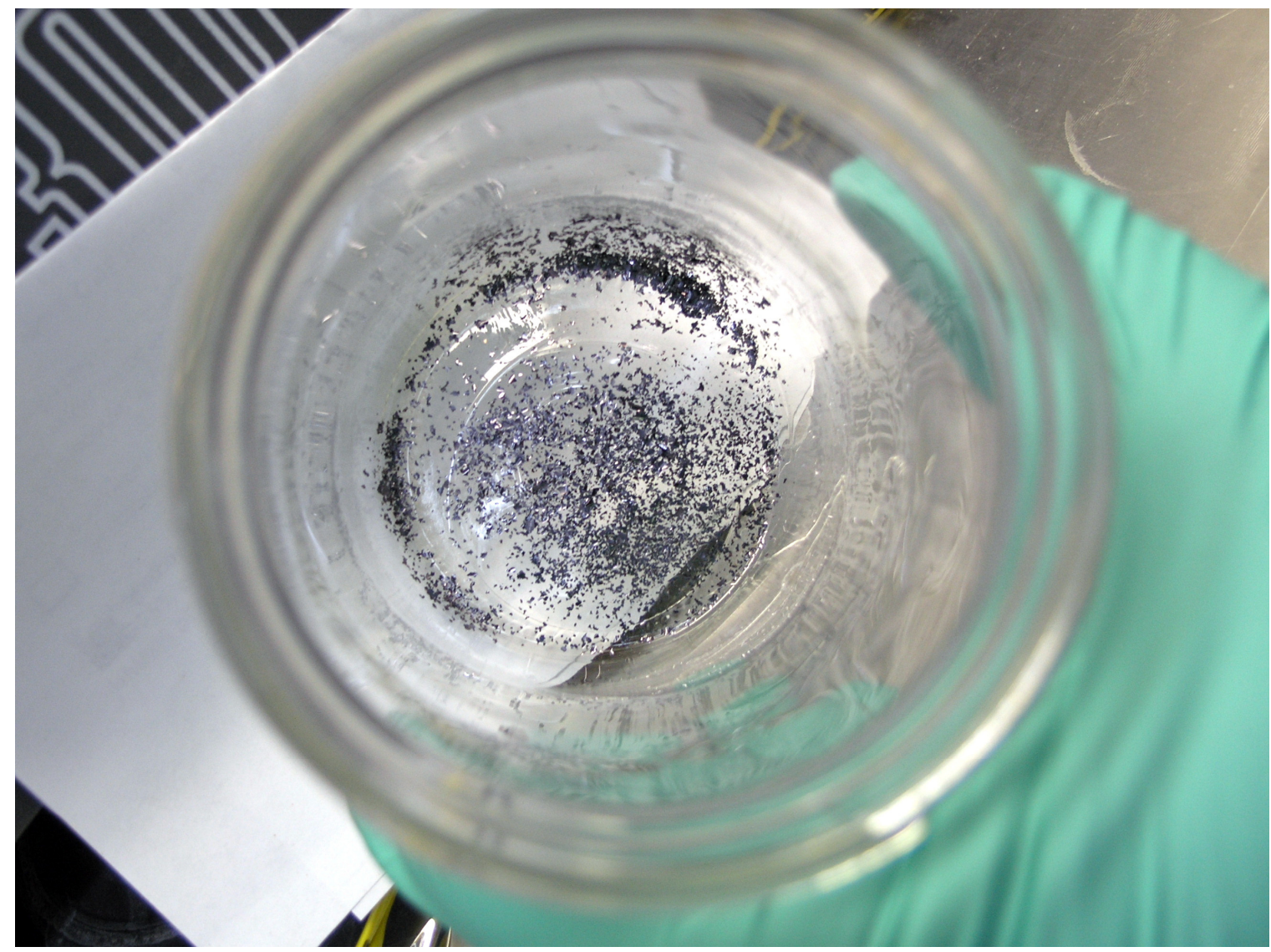

Figure 9. Flakes of $\mathrm{RuO}_{2}$ coatings poured from quartz tube used in Run 9.

Use of forceps to remove the screens from the quartz tube resulted in scratches and removal of some deposited material from the screens. Nonetheless, there was measurable weight gain on the screens caused by the black deposits (Table 2). The data indicate that weight gain of the mesh was $2.58 \mathrm{wt} \%$. Assuming the cylindrical wires in a mesh can only contact one another at either a point or an arched line, none of the surface is occluded, and the surface area is readily calculated from the mass of the mesh, diameter of the 
wire, and density of the wire material (in this case, 304 stainless steel). The calculated deposition, or loading, on the basis of surface area was $0.00131 \mathrm{~g} / \mathrm{cm}^{2}$. Because the mass of the screens increased only $0.0714 \mathrm{~g}$, the bulk of the $\mathrm{RuO}_{2}$ charged to the generator vessel $(0.6044 \mathrm{~g})$ either plated on the inside of the quartz tube or was removed from the gas by the scrubber solution.

For further tests, a decision was made to produce $\mathrm{RuO}_{4}$ by reaction of $\mathrm{RuO}_{2}$ with $\mathrm{NaIO}_{4}$ in water. This method seemed to produce useful quantities of $\mathrm{RuO}_{4}$ and was simple to implement.

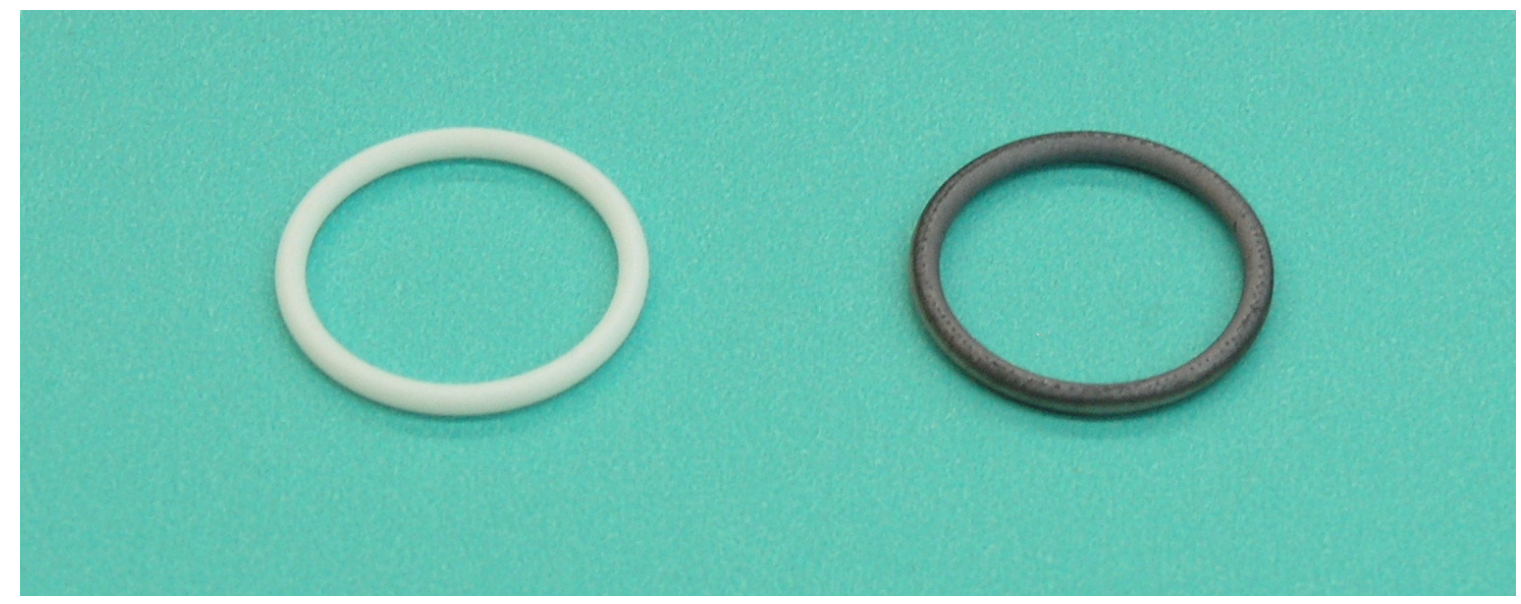

Figure 10. White Teflon O-ring (left), which was coated with $\mathrm{RuO}_{2}$ during Run 9 (right).

Table 2. Properties of wire mesh and amount of $\mathrm{RuO}_{2}$ deposited in Run 9. ${ }^{\mathrm{a}}$

\begin{tabular}{|l|c|}
\hline Mesh wire diameter & 0.01 in. $(0.0254 \mathrm{~cm})$ \\
\hline Density 304 stainless steel & $8.02 \mathrm{~g} / \mathrm{cm}^{3}$ \\
\hline Wire mass/length & $0.00406 \mathrm{~g} / \mathrm{cm}$ \\
\hline Wire surface/mass & $19.64 \mathrm{~cm}^{2} / \mathrm{g}$ \\
\hline Mass all 5 screens before deposition & $2.7679 \mathrm{~g}$ \\
\hline Mass all 5 screens after deposition & $2.8393 \mathrm{~g}$ \\
\hline Fractional loading of $\mathrm{RuO}_{2}$ & $2.58 \mathrm{wt} \%$ \\
\hline $\mathrm{RuO}_{2}$ loading/unit surface & $0.00131 \mathrm{~g} / \mathrm{cm}^{2}$ \\
\hline
\end{tabular}

${ }^{\text {a }}$ Deposits presumed to be $\mathrm{RuO}_{2}$ for purposes of discussion.

\subsection{Capacity and Mass Transfer Zone in Metallic Getters}

Runs 10-13 were conducted to obtain data on the capacity of metallic getters for ruthenium and on the length of the mass transfer zone for transfer of the volatile ruthenium to the solid surface. The equipment configuration of these tests is shown in Figure 3. A list of the experimental runs is provided in Table 3. In all runs, the sorbent (i.e., deposition surface or getter) was placed in a 1-in. ID quartz tube. Stainless steel (type 304) screens were cut into disks that fit against the ID of the tube. Steel wool was placed in the tube behind each screen, making sure there were no open gaps between the steel wool and the tube. The amount of steel wool varied between tests, and the packing density of the steel wool also varied (more details in subsequent tables). The $\mathrm{RuO}_{4}$ generator was charged, and the carrier gas flow was initiated after the 
sorbent column reached operating temperature. In every test the sorbent was followed by a caustic scrubber to remove any residual $\mathrm{RuO}_{4}$ from the gas stream. Because the $\mathrm{RuO}_{4}$ produces a color change in the solution, the scrubber gave a real-time indication of breakthrough from the column. Gas flow rate through the $\mathrm{RuO}_{4}$ generation bubbler was limited to $0.25 \mathrm{slpm}$ to avoid carrying an aqueous aerosol into the sorbent bed. Table 3 also lists the amount of $\mathrm{RuO}_{2}$ added to the $\mathrm{RuO}_{4}$ generation flask. That amount sets the maximum amount of $\mathrm{RuO}_{4}$ that could be produced. (The actual manufacturer's specification is $\mathrm{RuO}_{2} \cdot \mathrm{xH}_{2} \mathrm{O}$, with $\mathrm{x}$ undefined, but the ruthenium content stated as not less than $54 \mathrm{wt} \%$.) In these tests sufficient amounts of ruthenium were volatilized and subsequently gettered to permit reliable measurements of the mass gained by the sorbents. It should be noted that handling the steel wool, especially removing it from the quartz tube column, usually resulted in some loss of fines presumed to be due to breakage of the steel wool. Based on measured weight changes of steel wool that had been similarly handled, but not used in the sorption tests, the losses appeared to be insignificant.

Table 3. Tests of ruthenium trapping on wire mesh and steel wool. ${ }^{\mathrm{a}}$

\begin{tabular}{|l|c|c|c|c|c|c|}
\hline Run no. & $\begin{array}{c}\text { Sorbent } \\
\text { temp. } \\
\left({ }^{\circ} \mathrm{C}\right)\end{array}$ & $\begin{array}{c}\text { Sorbent } \\
\text { screen } \\
\text { mesh }\end{array}$ & $\begin{array}{c}\text { Carrier } \\
\text { gas }\end{array}$ & $\begin{array}{c}\text { Run time } \\
(\mathrm{h})\end{array}$ & $\begin{array}{c}\mathrm{RuO}_{2} \\
\text { charge } \\
(\mathrm{g})\end{array}$ & $\begin{array}{c}\text { Breakthrough } \\
\text { to scrubber? }\end{array}$ \\
\hline RO-10 & 150 & $40 \times 40$ & Ar & 5.90 & 0.5426 & Yes \\
\hline RO-11a ${ }^{\mathrm{b}}$ & 150 & $100 \times 100$ & Air & 7.35 & 0.5095 & No \\
\hline RO-11b & 150 & $100 \times 100$ & Air & 5.00 & 0.5203 & No \\
\hline RO-11c & 150 & $100 \times 100$ & Air & 6.83 & 0.5208 & No \\
\hline RO-11d & 150 & $100 \times 100$ & Air & 6.33 & 0.5184 & No \\
\hline RO-11e & 150 & $100 \times 100$ & Air & 6.75 & 0.5078 & No \\
\hline RO-11 total & & & & & 2.5768 & No \\
\hline RO-12 & 150 & $100 \times 100$ & Air & 5.50 & 0.5153 & No \\
\hline RO-13 & 250 & $100 \times 100$ & Air & 6.00 & 0.5023 & \\
\hline
\end{tabular}

${ }^{\text {a }}$ Common parameters in these tests: (1) Trapping material (or sorbent) housed in 1-in. ID quartz tube, (2) a section of grade 0000 steel wool followed each screen, and (3) the carrier gas flow rate was $0.25 \mathrm{slpm}$.

${ }^{\mathrm{b}}$ Run RO-11 was conducted using five separate charges of ruthenium, but the same sorbent and scrubber solution was kept throughout.

${ }^{c}$ This is based on visual observation of any color change in the scrubber solution. (Analytical results shown in Section 4.4 corroborate this observation.)

Tables 4-7 summarize the weight changes in the screens and steel wool packings for Runs 10-13, respectively. The sorbent loading is based on the initial mass of the material, expressed in weight percent. Specific (surface) loading $\left(\mathrm{g} / \mathrm{cm}^{2}\right)$ is based on the calculated surface area of the initial material. Surface area of the wire mesh is calculated from the wire diameter, mass of the mesh disk, and density of the stainless steel. Surface area of the steel wool is similarly calculated, but because filament width is specified by the manufacturers as a range, its equivalent diameter is assumed to be the midpoint of the range (specifically, 0.0008 in. or $0.0203 \mathrm{~mm})$. The linear packing density of the steel wool $(\mathrm{g} / \mathrm{cm})$ is based on the initial mass of material placed in a section of the tube and the length of the section. The last row of each table shows the weight gain $\left(\mathrm{RuO}_{2}\right.$ collected) on the screens and on the steel wool sections. The sum of these two gains is less than the mass of $\mathrm{RuO}_{2}$ placed in the generator because of deposition on the quartz tube. 
Six $40 \times 40$ mesh screens and six sections of steel wool (grade 0000) were placed in the quartz tube (column) for Run 10. Each screen was followed by a section of steel wool. The steel wool was loosely packed, except for the second section, which was inadvertently compressed to about twice the packing density of the first section when the third screen was installed (refer to Table 4). The initial appearance of the sorbent materials is shown in the top portion of Figure 11, and the appearance after deposition is shown in the lower portion of Figure 11. Deposition occurred on the inside surface of the tube just upstream of the first screen, presumably because the tube was warmer than room temperature because of thermal conduction through the quartz. Visually, material was deposited on all six screens and on about the first two-thirds of the last section of steel wool, which was much longer that the other sections at $63 / 4$ in $(17.15 \mathrm{~cm})$.

Mass increases in the sorbent materials, as shown in Table 4, indicate a loading of $\sim 0.2 \mathrm{wt} \%$ on the first screen and $\sim 6.3 \mathrm{wt} \%$ on the first steel wool section. Loading increased to $\sim 0.9 \mathrm{wt} \%$ on the second screen and to $\sim 11.2 \mathrm{wt} \%$ on the second steel wool section. This behavior is thought to be caused by a temperature gradient in the sorbent materials, caused by both heat losses at the end of the column and room temperature gas entering the column. There is nearly constant loading on screens and steel wool sections $2-4$. In screens 5 and 6 , and sections 5 and 6 , the weight loading decreases. When the ruthenium loading is calculated on the basis of mass per unit surface area, the loading is very close for screens and sections 2-4. Although there are variations in the specific surface loading on screens 1, 5, and 6 where either temperature gradients are the greatest or the concentration of sorbate is expected to decrease rapidly, the specific surface loading remains within an order of magnitude between screens and wool.

Run 11 was intended to ascertain if the sorbent materials would reach saturation. The run was conducted in the same manner as Run 10, but the linear packing density of the steel wool was greater. An average of $0.64 \mathrm{~g} / \mathrm{cm}$ as shown in Table 5. Another variation was that a total of five $\mathrm{RuO}_{4}$ generator charges were passed through the column. This was accomplished by conducting the equivalent of five single charge runs, but without changing the sorbent material or solution in the downstream scrubber. When the solution in the $\mathrm{RuO}_{4}$ generator became water clear, indicating that the ruthenium was depleted, the system was shut down and allowed to cool overnight. Before restarting with a fresh ruthenium charge the next business day, photographs of the sorbent column were taken. Figure 12 shows the initial condition of the column, screens and steel wool, and their appearance after each of the five sorption passes. Based on observed color changes in the column, the penetration depth of the sorbate into the column did not increase after the first ruthenium charge. Deposits were observed in the first 2-in. section of steel wool and in about the first half of the second $13 / 4$-in. $(4.45 \mathrm{~cm}$ ) section of steel wool. There was an uneven packing in the second section of steel wool that permitted a thin peninsula of deposits to reach the end of the second section. Loading on the first screen was $\sim 11.2 \mathrm{wt} \%$ and on the first steel wool section $\sim 70.7 \mathrm{wt} \%$. The surface area specific loading of both first screen and first steel wool section was $\sim 2.6 \times 10^{-3} \mathrm{~g} / \mathrm{cm}^{2}$. The loading in weight fraction and per specific area decreased substantially in the second screen and wool section pair, with no weight gain in materials downstream from the second pair. No color change was noted in the scrubber solution, indicating that no ruthenium passed the column. Following the second ruthenium charge, minor flaking of the deposits on the quartz tube was noted. After the fifth ruthenium charge when the packing was removed, flaking was more evident. 
Table 4. Measured mass of sorbent materials in Run 10 and calculated ruthenium loadings.

\begin{tabular}{|c|c|c|c|c|c|c|c|c|c|c|c|}
\hline \multicolumn{5}{|c|}{ Stainless steel wire mesh disks $(40 \times 40)$} & \multicolumn{7}{|c|}{ Steel wool packing (grade 0000) } \\
\hline \multirow{2}{*}{$\begin{array}{l}\text { Screen } \\
\text { disk no. }\end{array}$} & \multicolumn{2}{|c|}{ Mass } & \multirow{2}{*}{$\begin{array}{l}\text { Loading } \\
(\mathrm{wt} \%)\end{array}$} & \multirow{2}{*}{$\begin{array}{l}\text { Specific } \\
\text { loading } \\
\left(\mathrm{g} / \mathrm{cm}^{2}\right)\end{array}$} & \multirow{2}{*}{$\begin{array}{c}\text { Steel } \\
\text { wool } \\
\text { section no. }\end{array}$} & \multicolumn{2}{|c|}{ Mass } & \multirow{2}{*}{$\begin{array}{l}\text { Loading } \\
\text { (wt } \% \text { ) }\end{array}$} & \multirow{2}{*}{$\begin{array}{l}\text { Specific } \\
\text { loading } \\
\left(\mathrm{g} / \mathrm{cm}^{2}\right)\end{array}$} & \multicolumn{2}{|c|}{ Linear section } \\
\hline & $\begin{array}{c}\text { Before } \\
\text { (g) }\end{array}$ & $\begin{array}{l}\text { After } \\
(\mathrm{g})\end{array}$ & & & & $\begin{array}{c}\text { Before } \\
(\mathrm{g})\end{array}$ & $\begin{array}{l}\text { After } \\
(\mathrm{g})\end{array}$ & & & $\begin{array}{l}\text { Length } \\
\text { (in.) }\end{array}$ & $\begin{array}{l}\text { Packing density } \\
(\mathrm{g} / \mathrm{cm})\end{array}$ \\
\hline RO-10-01 & 0.5524 & 0.5534 & 0.1810 & $9.219 \mathrm{E}-05$ & RO-10-1w & 0.4547 & 0.4833 & 6.2899 & $2.511 \mathrm{E}-04$ & 0.5625 & 0.3183 \\
\hline RO-10-02 & 0.5543 & 0.5592 & 0.8840 & 4.502E-04 & RO-10-2w & 0.4617 & 0.5135 & 11.2194 & $4.480 \mathrm{E}-04$ & 0.2500 & 0.7271 \\
\hline RO-10-03 & 0.5582 & 0.5615 & 0.5912 & $3.011 \mathrm{E}-04$ & RO-10-3w & 0.4929 & 0.5507 & 11.7265 & $4.682 \mathrm{E}-04$ & 0.5000 & 0.3881 \\
\hline RO-10-04 & 0.5544 & 0.5594 & 0.9019 & $4.593 \mathrm{E}-04$ & RO-10-4w & 0.4204 & 0.4673 & 11.1560 & $4.454 \mathrm{E}-04$ & 0.6250 & 0.2648 \\
\hline RO-10-05 & 0.5522 & 0.5570 & 0.8693 & 4.427E-04 & RO-10-5w & 0.4760 & 0.5228 & 9.8319 & $3.926 \mathrm{E}-04$ & 0.5625 & 0.3332 \\
\hline RO-10-06 & 0.5571 & 0.5599 & 0.5026 & $2.560 \mathrm{E}-04$ & RO-10-6w & 5.7070 & 5.8528 & 2.5548 & $1.020 \mathrm{E}-04$ & 6.7500 & 0.3329 \\
\hline Total & 3.3286 & 3.3504 & 0.6549 & $3.335 \mathrm{E}-04$ & & & & & & Average & 0.3940 \\
\hline
\end{tabular}

Note: Total $\mathrm{RuO}_{2}$ collected on all six wire mesh disks was $0.0218 \mathrm{~g}$, and the total collected on all the steel wool packing was $0.3777 \mathrm{~g}$.

Table 5. Measured mass of sorbent materials in Run 11 and calculated ruthenium loadings.

\begin{tabular}{|c|c|c|c|c|c|c|c|c|c|c|c|}
\hline \multicolumn{5}{|c|}{ Stainless steel wire mesh disks $(100 \times 100)$} & \multicolumn{7}{|c|}{ Steel wool packing (grade 0000) } \\
\hline \multirow{2}{*}{$\begin{array}{l}\text { Screen } \\
\text { disk no. }\end{array}$} & \multicolumn{2}{|c|}{ Mass } & \multirow{2}{*}{$\begin{array}{l}\text { Loading } \\
\left(\mathrm{wt}^{0} \%\right)\end{array}$} & \multirow{2}{*}{$\begin{array}{l}\text { Specific } \\
\text { loading } \\
\left(\mathrm{g} / \mathrm{cm}^{2}\right)\end{array}$} & \multirow{2}{*}{$\begin{array}{c}\text { Steel } \\
\text { wool } \\
\text { section no. }\end{array}$} & \multicolumn{2}{|c|}{ Mass } & \multirow{2}{*}{$\begin{array}{c}\text { Loading } \\
(\mathrm{wt} \%)\end{array}$} & \multirow{2}{*}{$\begin{array}{l}\text { Specific } \\
\text { loading } \\
\left(\mathrm{g} / \mathrm{cm}^{2}\right)\end{array}$} & \multicolumn{2}{|c|}{ Linear section } \\
\hline & $\begin{array}{c}\text { Before } \\
(\mathrm{g})\end{array}$ & $\begin{array}{l}\text { After } \\
(\mathrm{g})\end{array}$ & & & & $\begin{array}{c}\text { Before } \\
(\mathrm{g})\end{array}$ & $\begin{array}{c}\text { After } \\
(\mathrm{g})\end{array}$ & & & $\begin{array}{l}\text { Length } \\
\text { (in.) }\end{array}$ & $\begin{array}{c}\text { Packing density } \\
(\mathrm{g} / \mathrm{cm})\end{array}$ \\
\hline RO-11-01 & 0.3027 & 0.3365 & 11.1662 & $2.559 \mathrm{E}-03$ & RO-11-01w & 2.7913 & 4.7636 & 70.6588 & $2.821 \mathrm{E}-03$ & 2.0000 & 0.5495 \\
\hline RO-11-02 & 0.3052 & 0.3074 & 0.7208 & $1.652 \mathrm{E}-04$ & RO-11-02w & 2.7885 & 2.7949 & 0.2295 & 9.164E-06 & 1.7500 & 0.6273 \\
\hline RO-11-03 & 0.3018 & 0.3019 & 0.0331 & $7.593 \mathrm{E}-06$ & RO-11-03w & 3.6073 & 3.6035 & $\mathrm{a}$ & $\mathrm{a}$ & 1.5000 & 0.9468 \\
\hline RO-11-04 & 0.3045 & 0.3048 & 0.0985 & $2.258 \mathrm{E}-05$ & RO-11-04w & 3.0309 & 3.0277 & $\mathrm{a}$ & $\mathrm{a}$ & 2.0000 & 0.5966 \\
\hline RO-11-05 & 0.3025 & 0.3021 & $\mathrm{a}$ & $\mathrm{a}$ & RO-11-05w & 2.1846 & 2.1810 & $\mathrm{a}$ & $\mathrm{a}$ & 1.7500 & 0.4915 \\
\hline RO-11-06 & 0.3023 & 0.3022 & $\mathrm{a}$ & $\mathrm{a}$ & RO-11-06w & 2.3033 & 2.3001 & $\mathrm{a}$ & $\mathrm{a}$ & 1.5000 & 0.6045 \\
\hline Total & 1.8190 & 1.8549 & 1.9736 & $4.523 \mathrm{E}-04$ & & & & & & Average & 0.6360 \\
\hline
\end{tabular}

${ }^{a}$ A small negative value was calculated because the measured mass is within instrument error or indicates a small loss of sample.

Note: Total $\mathrm{RuO}_{2}$ collected on all six wire mesh disks was $0.0364 \mathrm{~g}$, and the total collected on all the steel wool packing was $1.9787 \mathrm{~g}$. 
Table 6. Measured mass of sorbent materials in Run 12 and calculated ruthenium loadings.

\begin{tabular}{|c|c|c|c|c|c|c|c|c|c|c|c|}
\hline \multicolumn{5}{|c|}{ Stainless steel wire mesh disks $(100 \times 100)$} & \multicolumn{7}{|c|}{ Steel wool packing (grade 0000) } \\
\hline \multirow[b]{2}{*}{$\begin{array}{l}\text { Screen } \\
\text { disk no. }\end{array}$} & \multicolumn{2}{|c|}{ Mass } & \multirow{2}{*}{$\begin{array}{l}\text { Loading } \\
(\mathrm{wt} \%)\end{array}$} & \multirow{2}{*}{$\begin{array}{l}\text { Specific } \\
\text { loading } \\
\left(\mathrm{g} / \mathrm{cm}^{2}\right)\end{array}$} & \multirow{2}{*}{$\begin{array}{c}\text { Steel } \\
\text { wool } \\
\text { section no. }\end{array}$} & \multicolumn{2}{|c|}{ Mass } & \multirow[b]{2}{*}{$\begin{array}{l}\text { Loading } \\
(w t \%)\end{array}$} & \multirow{2}{*}{$\begin{array}{l}\text { Specific } \\
\text { loading } \\
\left(\mathrm{g} / \mathrm{cm}^{2}\right)\end{array}$} & \multicolumn{2}{|c|}{ Linear section } \\
\hline & $\begin{array}{c}\text { Before } \\
(\mathrm{g})\end{array}$ & $\begin{array}{c}\text { After } \\
(\mathrm{g})\end{array}$ & & & & $\begin{array}{c}\text { Before } \\
(\mathrm{g})\end{array}$ & $\begin{array}{l}\text { After } \\
(\mathrm{g})\end{array}$ & & & $\begin{array}{l}\text { Length } \\
\text { (in.) }\end{array}$ & $\begin{array}{l}\text { Packing density } \\
(\mathrm{g} / \mathrm{cm})\end{array}$ \\
\hline RO-12-01 & 0.3036 & 0.3130 & 3.0962 & 7.096E-04 & RO-12-01w & 1.0726 & 1.3062 & 21.7789 & $8.696 \mathrm{E}-04$ & 0.6250 & 0.6757 \\
\hline RO-12-02 & 0.3045 & 0.3126 & 2.6601 & $6.096 \mathrm{E}-04$ & RO-12-02w & 1.1770 & 1.2873 & 9.3713 & $3.742 \mathrm{E}-04$ & 0.6250 & 0.7414 \\
\hline RO-12-03 & 0.3042 & 0.3063 & 0.6903 & $1.582 \mathrm{E}-04$ & RO-12-03w & 0.9291 & 0.9381 & 0.9687 & $3.868 \mathrm{E}-05$ & 0.6250 & 0.5853 \\
\hline RO-12-04 & 0.3054 & 0.3055 & 0.0327 & 7.504E-06 & RO-12-04w & 1.1268 & 1.1259 & $\mathrm{a}$ & $\mathrm{a}$ & 0.6250 & 0.7098 \\
\hline RO-12-05 & 0.3047 & 0.3050 & 0.0985 & $2.256 \mathrm{E}-05$ & RO-12-05w & 1.8703 & 1.8695 & $\mathrm{a}$ & $\mathrm{a}$ & 1.0000 & 0.7363 \\
\hline Total & 1.5224 & 1.5424 & 1.3137 & $3.011 \mathrm{E}-04$ & & & & & & Average & 0.6897 \\
\hline
\end{tabular}

${ }^{\text {a }}$ A small negative value was calculated because the measured mass is within instrument error or indicates a small loss of sample.

Note: Total $\mathrm{RuO}_{2}$ collected on all five wire mesh disks was $0.0196 \mathrm{~g}$, and the total collected on all the steel wool packing was $0.3529 \mathrm{~g}$.

Table 7. Measured mass of sorbent materials in Run 13 and calculated ruthenium loadings.

\begin{tabular}{|c|c|c|c|c|c|c|c|c|c|c|c|}
\hline \multicolumn{5}{|c|}{ Stainless steel wire mesh disks $(100 \times 100)$} & \multicolumn{7}{|c|}{ Steel wool packing (grade 0000 ) } \\
\hline \multirow{2}{*}{$\begin{array}{l}\text { Screen } \\
\text { disk no. }\end{array}$} & \multicolumn{2}{|c|}{ Mass } & \multirow{2}{*}{$\begin{array}{l}\text { Loading } \\
(\mathrm{wt} \%)\end{array}$} & \multirow{2}{*}{$\begin{array}{l}\text { Specific } \\
\text { loading } \\
\left(\mathrm{g} / \mathrm{cm}^{2}\right)\end{array}$} & \multirow{2}{*}{$\begin{array}{c}\text { Steel } \\
\text { wool } \\
\text { section no. }\end{array}$} & \multicolumn{2}{|c|}{ Mass } & \multirow{2}{*}{$\begin{array}{l}\text { Loading } \\
\text { (wt } \%)\end{array}$} & \multirow{2}{*}{$\begin{array}{l}\text { Specific } \\
\text { loading } \\
\left(\mathrm{g} / \mathrm{cm}^{2}\right)\end{array}$} & \multicolumn{2}{|c|}{ Linear section } \\
\hline & $\begin{array}{l}\text { Before } \\
(\mathrm{g})\end{array}$ & $\begin{array}{l}\text { After } \\
(\mathrm{g})\end{array}$ & & & & $\begin{array}{l}\text { Before } \\
(\mathrm{g})\end{array}$ & $\begin{array}{l}\text { After } \\
(\mathrm{g})\end{array}$ & & & $\begin{array}{l}\text { Length } \\
\text { (in.) }\end{array}$ & $\begin{array}{l}\text { Packing density } \\
\qquad(\mathrm{g} / \mathrm{cm})\end{array}$ \\
\hline RO-13-01 & 0.3034 & 0.3893 & 28.3125 & $6.488 \mathrm{E}-03$ & RO-13-01w & 1.1298 & 1.3024 & 15.2770 & $6.100 \mathrm{E}-04$ & 0.6250 & 0.7117 \\
\hline RO-13-02 & 0.3043 & 0.3039 & $\mathrm{a}$ & $\mathrm{a}$ & RO-13-02w & 0.9697 & 0.9656 & $\mathrm{a}$ & $\mathrm{a}$ & 0.6250 & 0.6108 \\
\hline RO-13-03 & 0.3036 & 0.3035 & $\mathrm{a}$ & $\mathrm{a}$ & RO-13-03w & 1.0914 & 1.0855 & $\mathrm{a}$ & $\mathrm{a}$ & 0.6250 & 0.6875 \\
\hline RO-13-04 & 0.3039 & 0.3042 & 0.0987 & $2.262 \mathrm{E}-05$ & RO-13-04w & 1.1551 & 1.1561 & 0.0866 & $3.457 \mathrm{E}-06$ & 0.6250 & 0.7276 \\
\hline RO-13-05 & 0.3038 & 0.3041 & 0.0987 & $2.263 \mathrm{E}-05$ & RO-13-05w & 1.9489 & 1.9511 & 0.1129 & $4.507 \mathrm{E}-06$ & 1.0000 & 0.7673 \\
\hline Total & 1.5190 & 1.6050 & 5.6616 & $1.297 \mathrm{E}-03$ & & & & & & Average & 0.7010 \\
\hline
\end{tabular}

${ }^{a}$ A small negative value was calculated because the measured mass is within instrument error or indicates a small loss of sample.

Note: Total $\mathrm{RuO}_{2}$ collected on all five wire mesh disks was $0.0859 \mathrm{~g}$, and the total collected on all the steel wool packing was $0.1726 \mathrm{~g}$. 


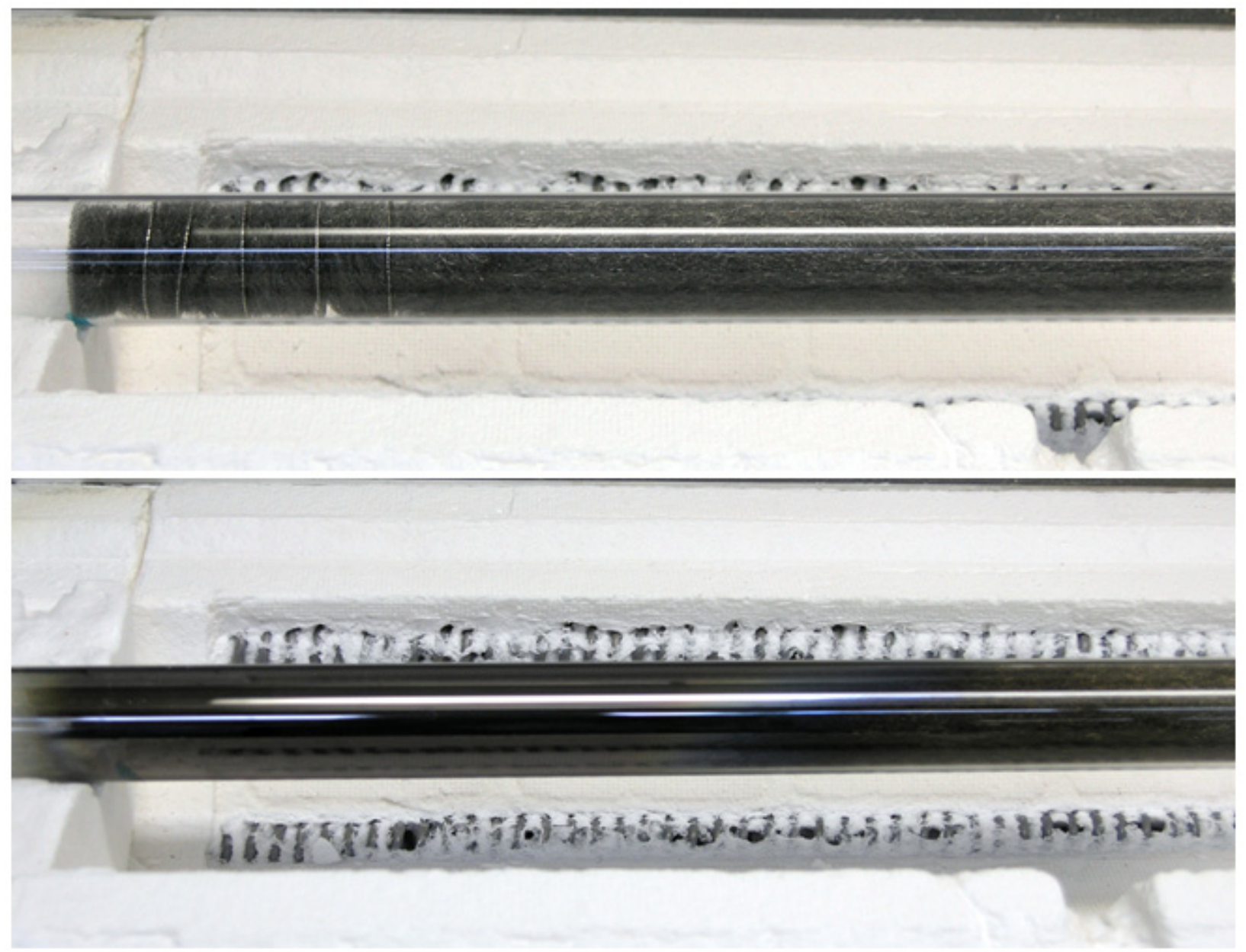

Figure 11. Initial appearance of screens and steel wool packing in column (top) and appearance after deposition of ruthenium (bottom) in Run 10. 


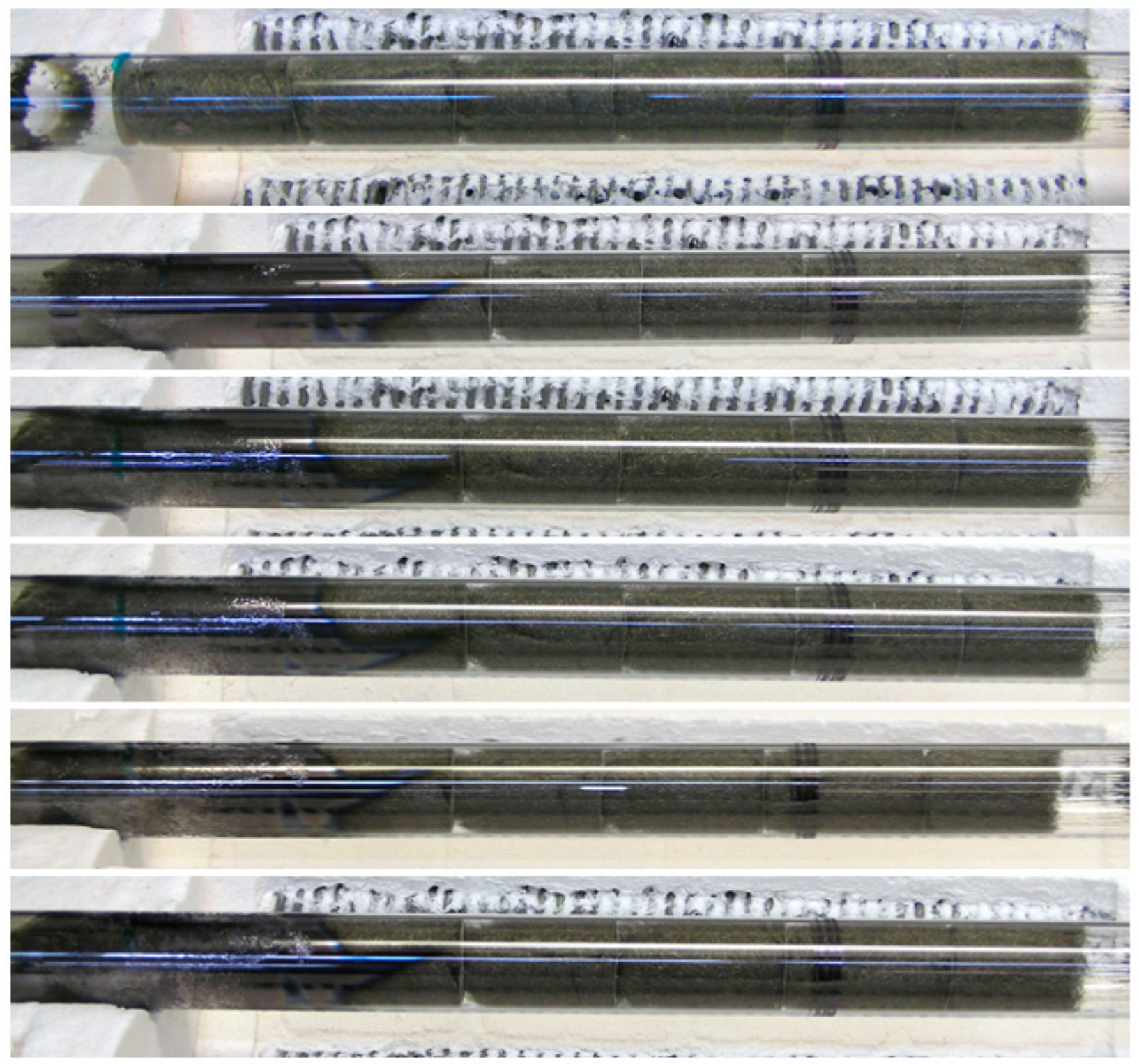

Figure 12. Appearance of column with screens and steel wool packing in Run 11: Initial condition before deposition (top) and cumulative condition after each of five separate depositions (from top to bottom).

Figures 13 is a photograph of the Run 11 quartz column after the wire mesh screens and steel wool were removed. The first steel wool section removed from the tube, shown in Figure 14, had thin glossy deposits on the radius, which appeared to have been pulled from the quartz surface. Some loose flakes of glossy material were also collected. The visual evidence suggests the glossy deposits adhered more strongly to the steel wool and were released from the inside surface of the quartz tube. Figure 15 is a photograph of the first five Run 11 screens removed from the column. The first two screens were coated with black deposits but the trailing screens showed little to no change compared to unused screens. This is consistent with the measured weight changes in Table 5. 


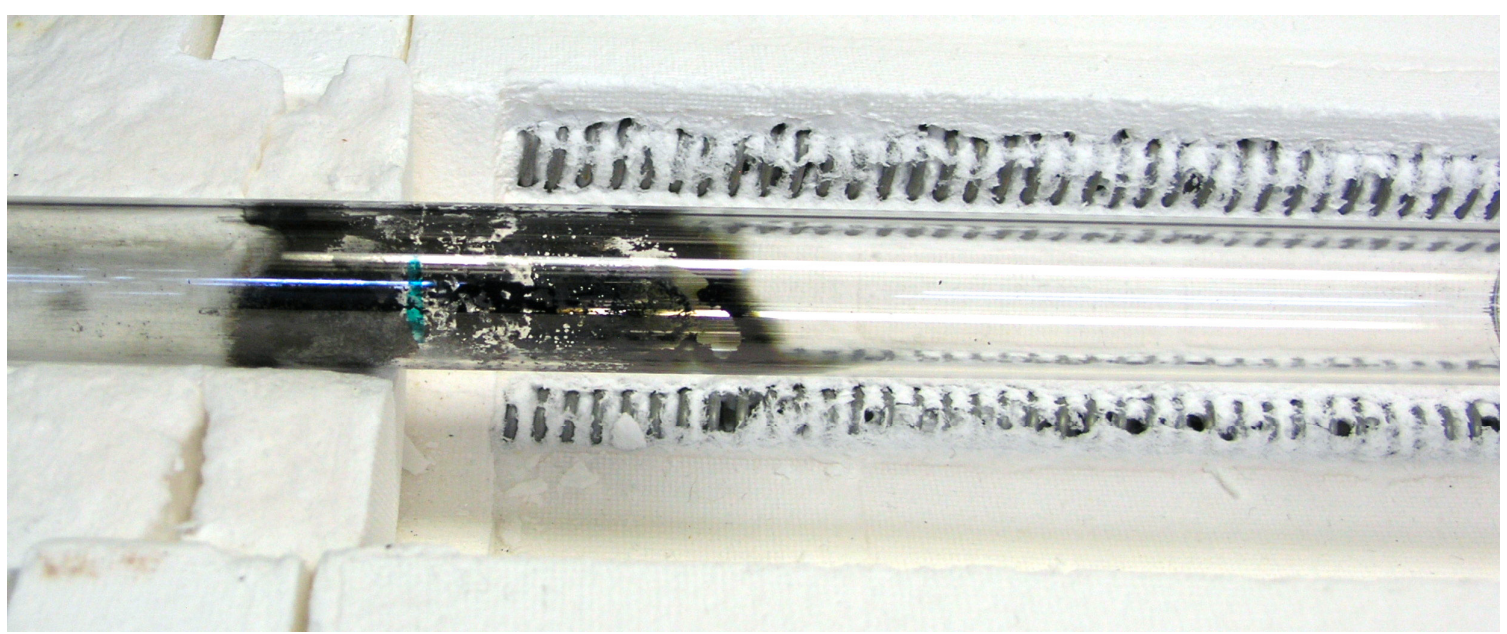

Figure 13. Appearance of quartz tube used in Run 11 after the screens and wool were removed.

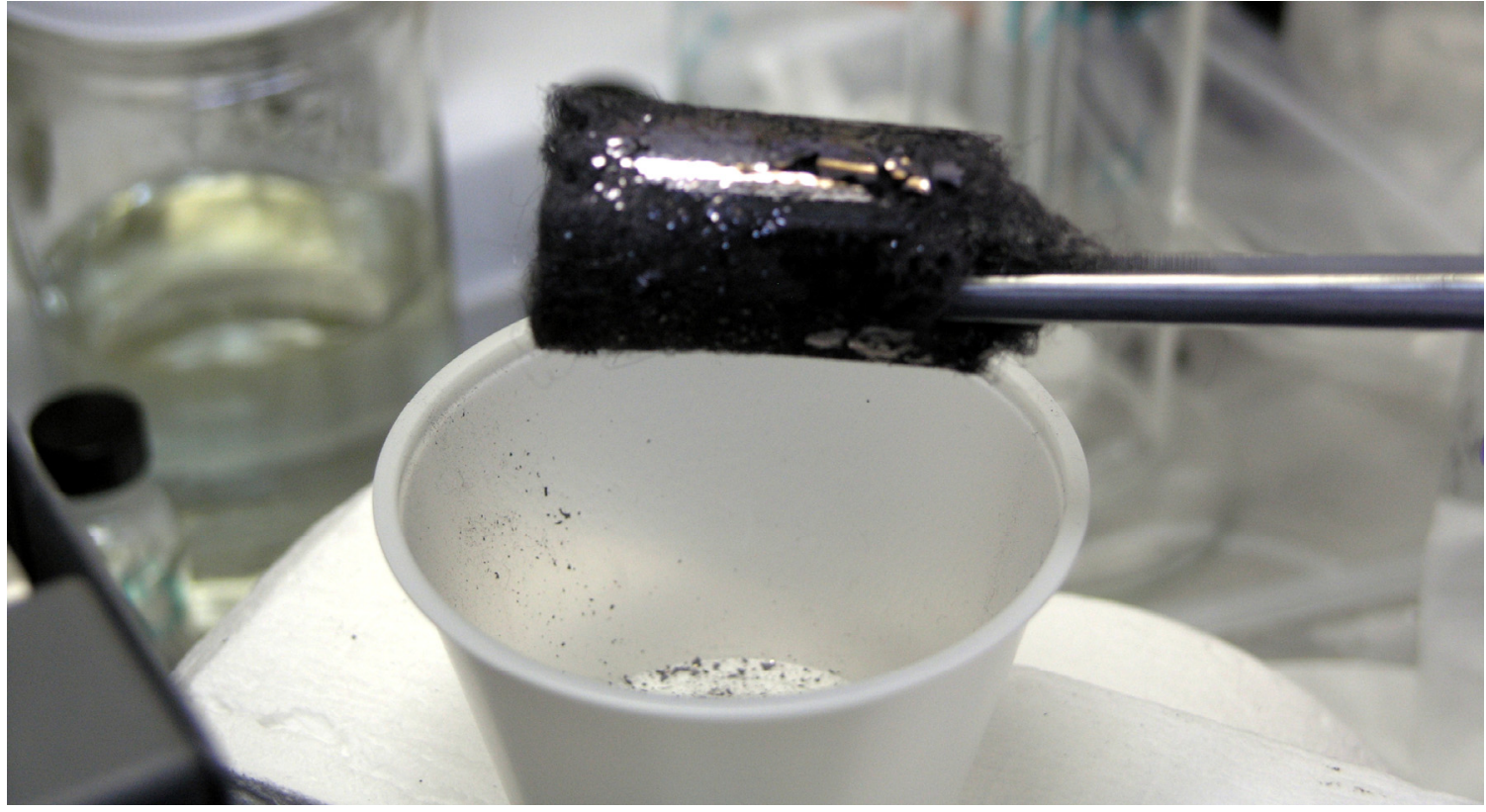

Figure 14. Steel wool section RO-11-01w removed from Run 11 quartz column. Note the glossy flake-like deposits adhered to the steel wool, which were evidently pulled from the quartz surface. 


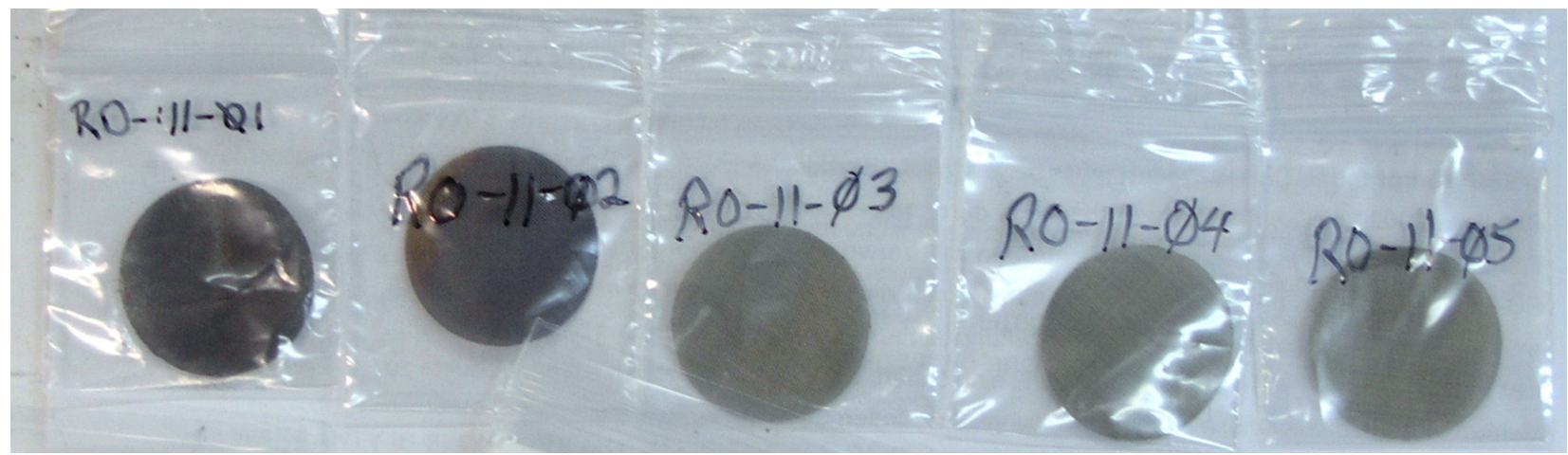

Figure 15. Screens removed from the Run 11 column showing decrease in blackening caused by deposition.

As shown in Table 5, the specific loading of screen RO-11-01 was calculated at $\sim 2.6 \times 10^{-3} \mathrm{~g} / \mathrm{cm}^{2}$. Assuming the deposits are $\mathrm{RuO}_{2}$, which has a density of $6.97 \mathrm{~g} / \mathrm{cm}^{3}$, the mean thickness of the deposits are calculated to be $3.7 \mu \mathrm{m}$. A piece was cut from the disk, mounted in epoxy and polished to allow visualization of the wire looking down at the cut edge. A photomicrograph of the polished section is shown in Figure 16. It shows the base metal of the wire (white) and a thin deposit (grey to black). Based on the scale shown in the photomicrograph, the deposited layer is estimated at $2 \mu \mathrm{m}$ thick. This is reasonably consistent with the estimate based on weight gain. What appears to be the thicker deposits at the ends of the S-shaped cross section of the wire is an artifact of the angle of the cut through the section.

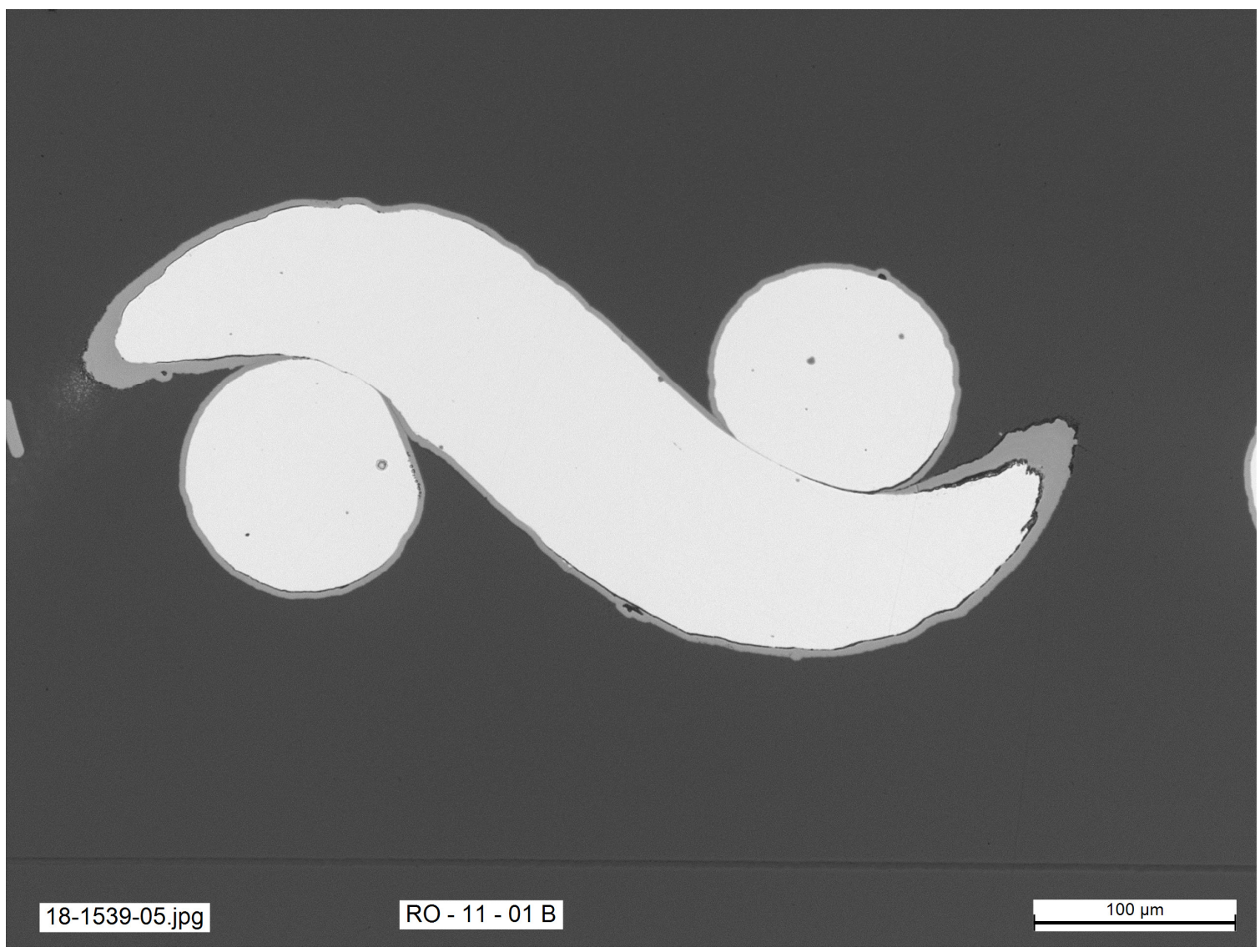

Figure 16. Photomicrograph of polished section of screen RO-11-01 from Run 11. 
Figure 17 is a scanning electron microscope (SEM) image of screen RO-11-01. It shows the that the deposited layers are uniform. Some remnants of the coatings scrapped from handling the screen can be seen adhering to the surface. Energy dispersive spectroscopy of the deposits reveal they are composed of ruthenium and $\mathrm{O}_{2}$, see Figure 18 (the carbon peak is an artifact of the carbon holder).

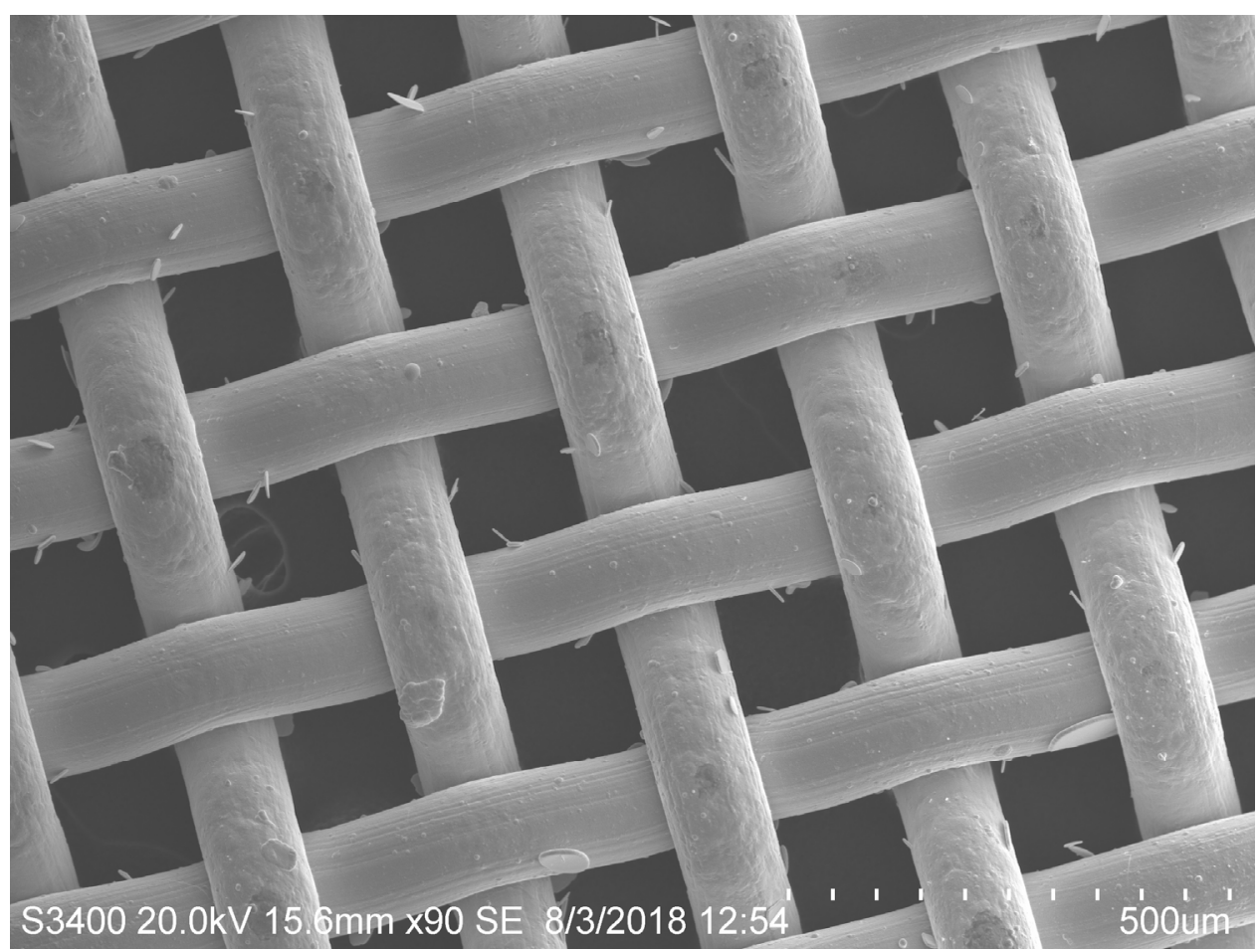

Figure 17. SEM image of screen RO-11-01 in Run 11.

F:\{SEM Images and Data\}8-3-2018 Mesh ScreensłR0-11-01A.spc

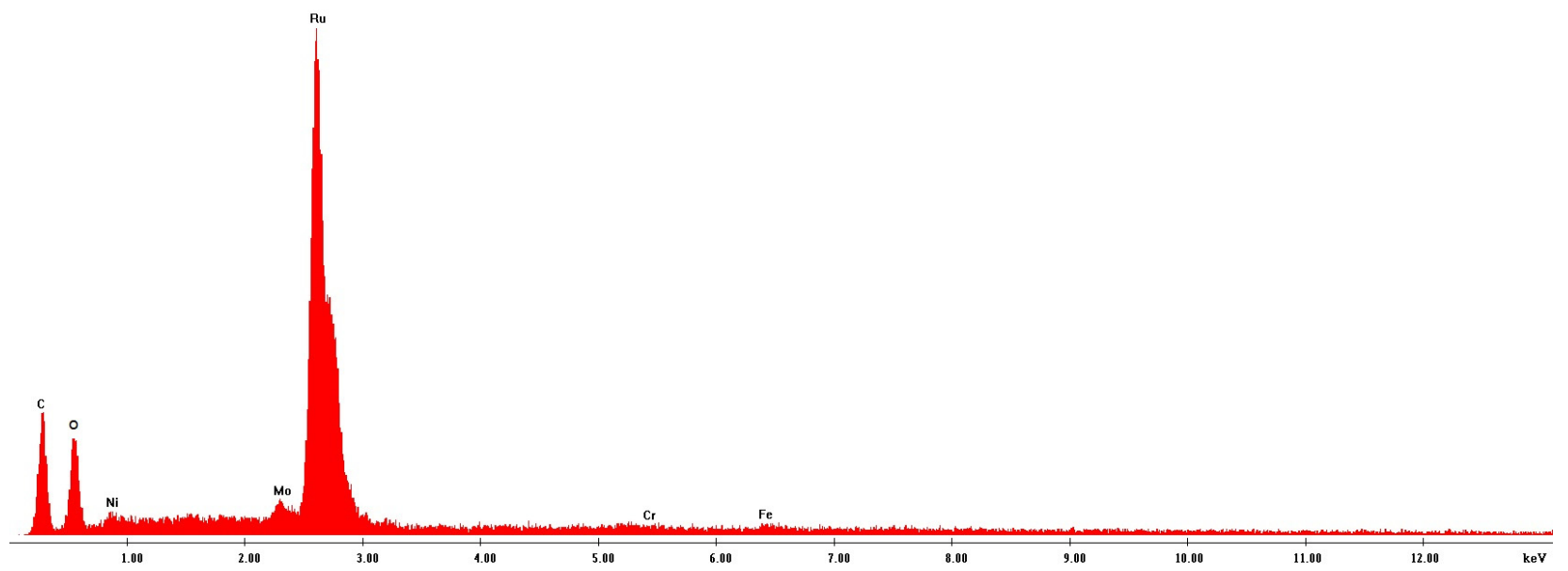

Figure 18. Energy dispersive spectroscopy of screen RO-11-01 from Run 11. 
Run 12 was conducted using the same gas flow rate and sorbent temperature as in Run 11. The section lengths of the steel wool sorbent were made shorter in an attempt to get better resolution of the depth of the deposition zone. Only one $\mathrm{RuO}_{4}$ generator charge was passed through the sorbents. Average packing of the steel wool was only slightly higher than in Run 11. Figure 19 shows the packing before and after the run. Deposits are evident on the quartz tube and on the first three screens and steel wool sections, and visually the depth of $\mathrm{RuO}_{4}$ penetration into the sorbent is sharply defined. Post-run weighing and calculated results are shown in Table 6 . The first three screens and steel wool sections had significant weight gains. The specific loading of the first screen was $7.1 \times 10^{-4} \mathrm{~g} / \mathrm{cm}^{2}$ and that of the first steel wool section was $8.7 \times 10^{-4} \mathrm{~g} / \mathrm{cm}^{2}$. In the second pair, the loading on the screen was $6.1 \times 10^{-4} \mathrm{~g} / \mathrm{cm}^{2}$ and the loading on the steel wool was $3.7 \times 10^{-4} \mathrm{~g} / \mathrm{cm}^{2}$. Downstream from the second pair, the percentage variation between screens and steel wool increased. The data suggests $\mathrm{RuO}_{4}$ penetration of about $1.9 \mathrm{in} .(4.83 \mathrm{~cm})$ into the bed.

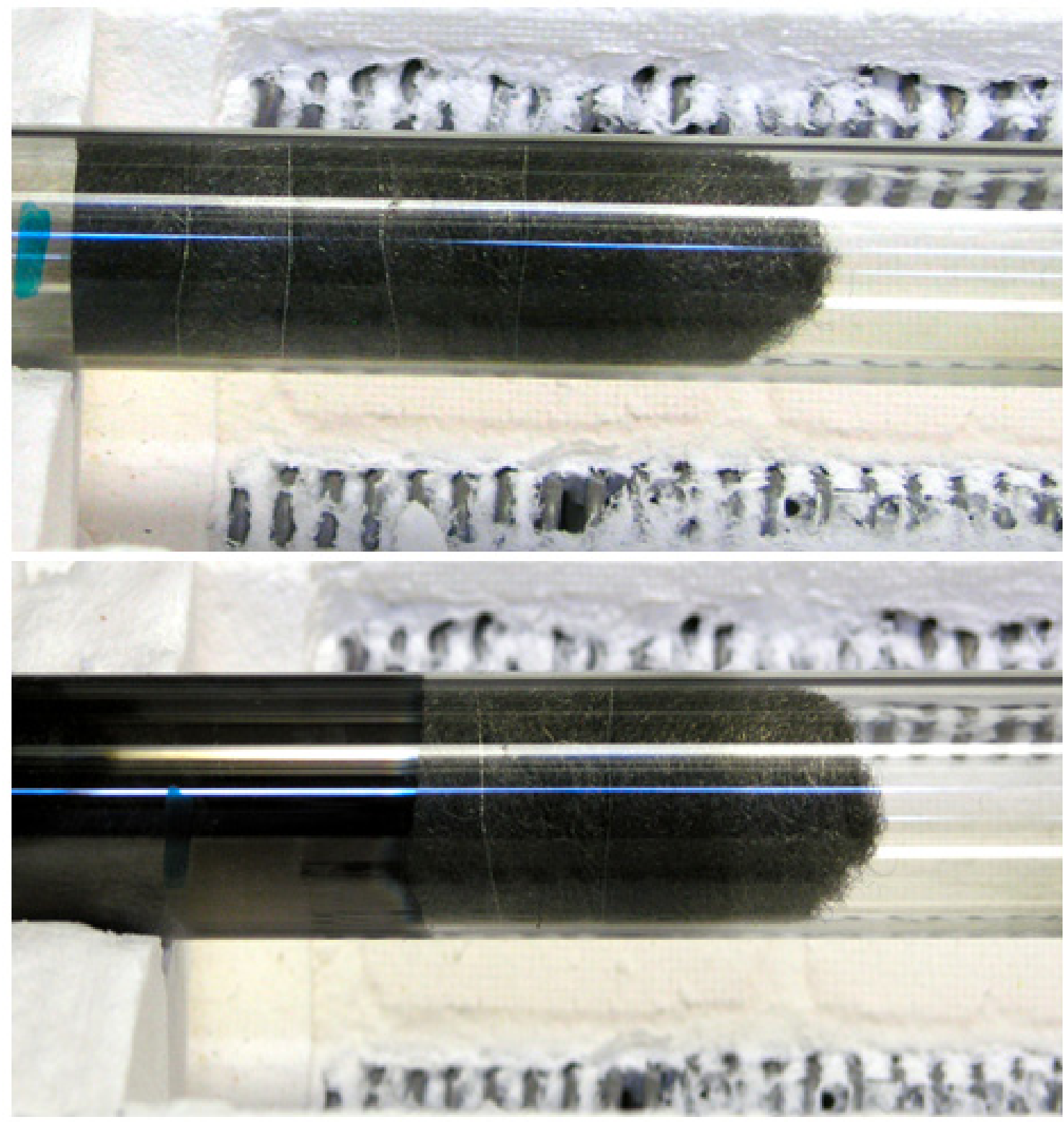

Figure 19. Initial appearance of screens and steel wool packing in column (top) and appearance after deposition of ruthenium (bottom) in Run 12. 
A photograph of the screens removed from the column at the end of Run 12 is shown in Figure 20. Nearly uniform deposits are evident on the first three screens. The fourth screen shows deposits in the central area of the disk with virtually no visible deposits on the periphery. Figure 21 shows the ends of the first three sections of steel wool. Deposits seem uniform on the first two sections, but the third section has deposits on only the central region. This suggests that the core of the second section of steel wool was less dense than the outer portion - an artifact of hand rolling the steel wool.

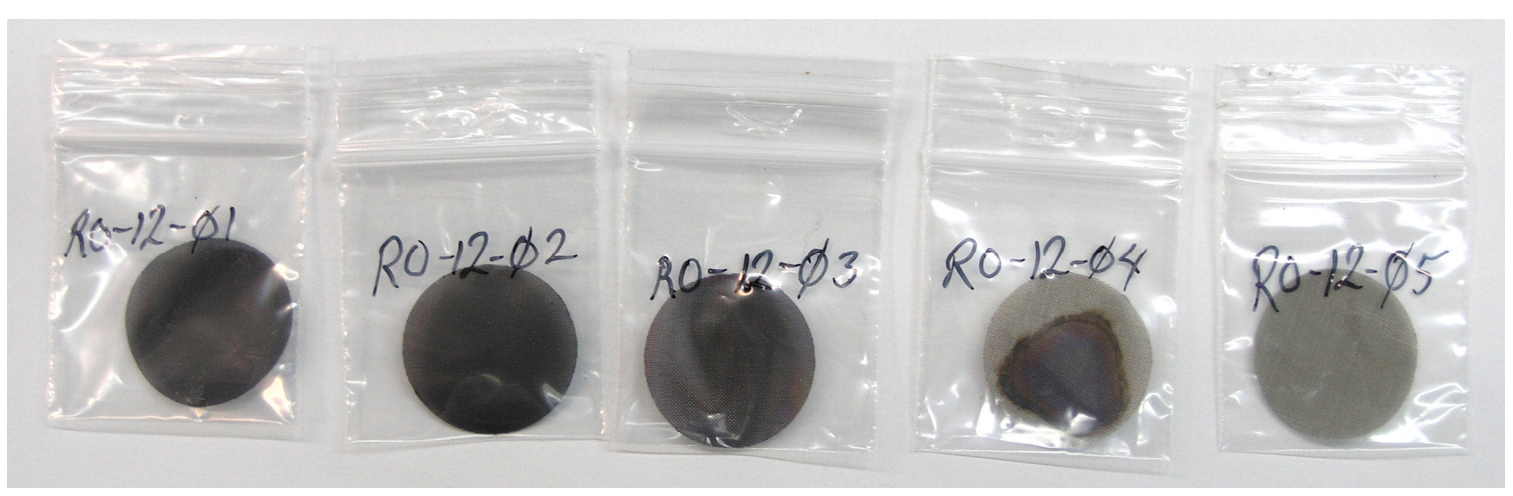

Figure 20. Post-Run 12 screens recovered from column.

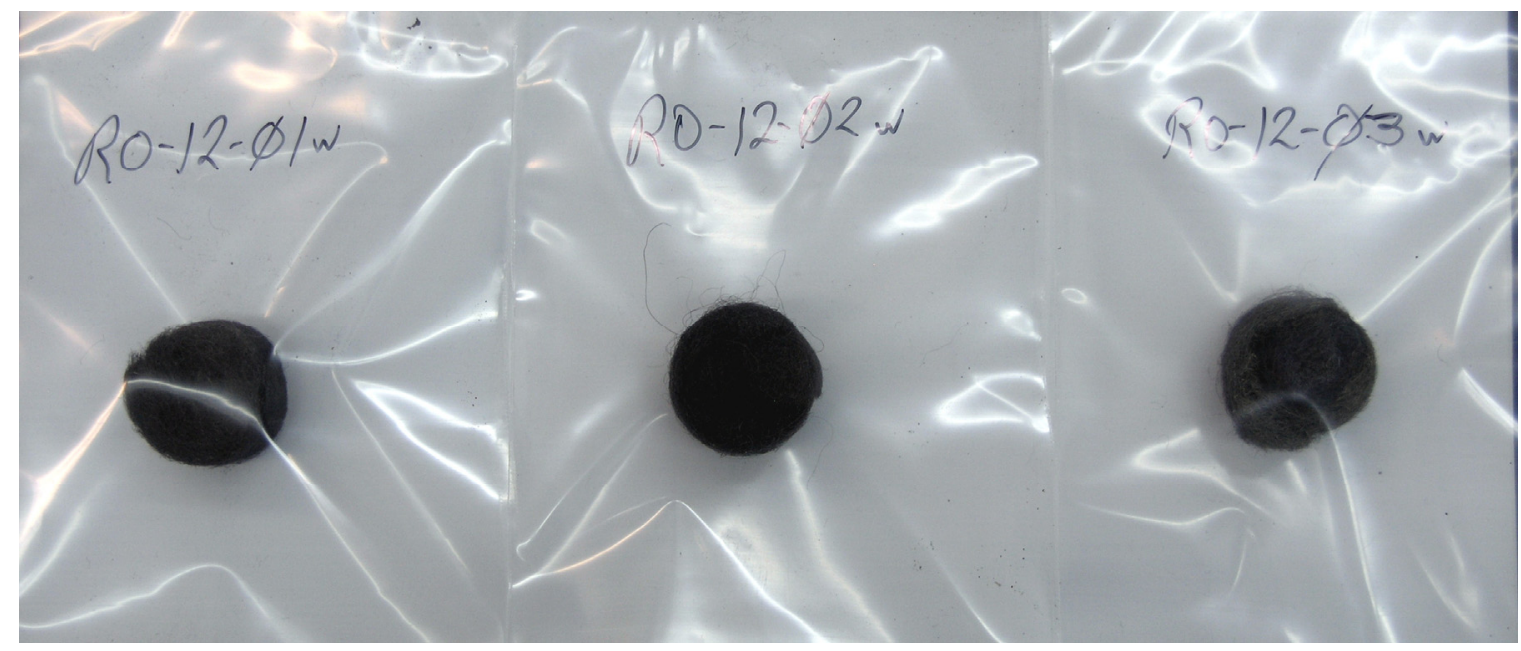

Figure 21. First three sections of steel wool removed from column at end of Run 12.

In Run 12 the sections of steel wool were short enough to visualize a deposition gradient through the bed. Considering that the packing density of the steel wool sections varied up to $15 \%$ from the mean, a reasonable bed-depth coordinate is the mass of steel wool. The available surface area is directly proportional to the mass (value is $\sim 250 \mathrm{~cm}^{2} / \mathrm{g}$ ). The mesh screens are ignored for this determination because they are considered thin beds over which the gas phase concentration of ruthenium changes insignificantly. In Figure 23 the specific loading of the steel wool is plotted at the midpoint mass of each steel wool section as a function of cumulative steel wool mass in the bed. A very rapid decrease in ruthenium loading per square centimeter of bed surface is shown. The screen mesh has a very small width ( $\sim 0.0045$ in.), and each screen is followed by a steel wool section. Plotting the specific loading of ruthenium on the screen mesh as a function of cumulative steel wool is shown in Figure 23, which uses the same coordinate system as in Figure 22. Again rapid decreases in the specific ruthenium loading are seen. The loading on the first screen is lower than extrapolation from the two succeeding screens would suggest. It is thought that the first screen was likely cooler than the remainder of the bed because of the cool gas stream entering the bed of sorbent. This is consistent with the deposition rate increasing with increasing 


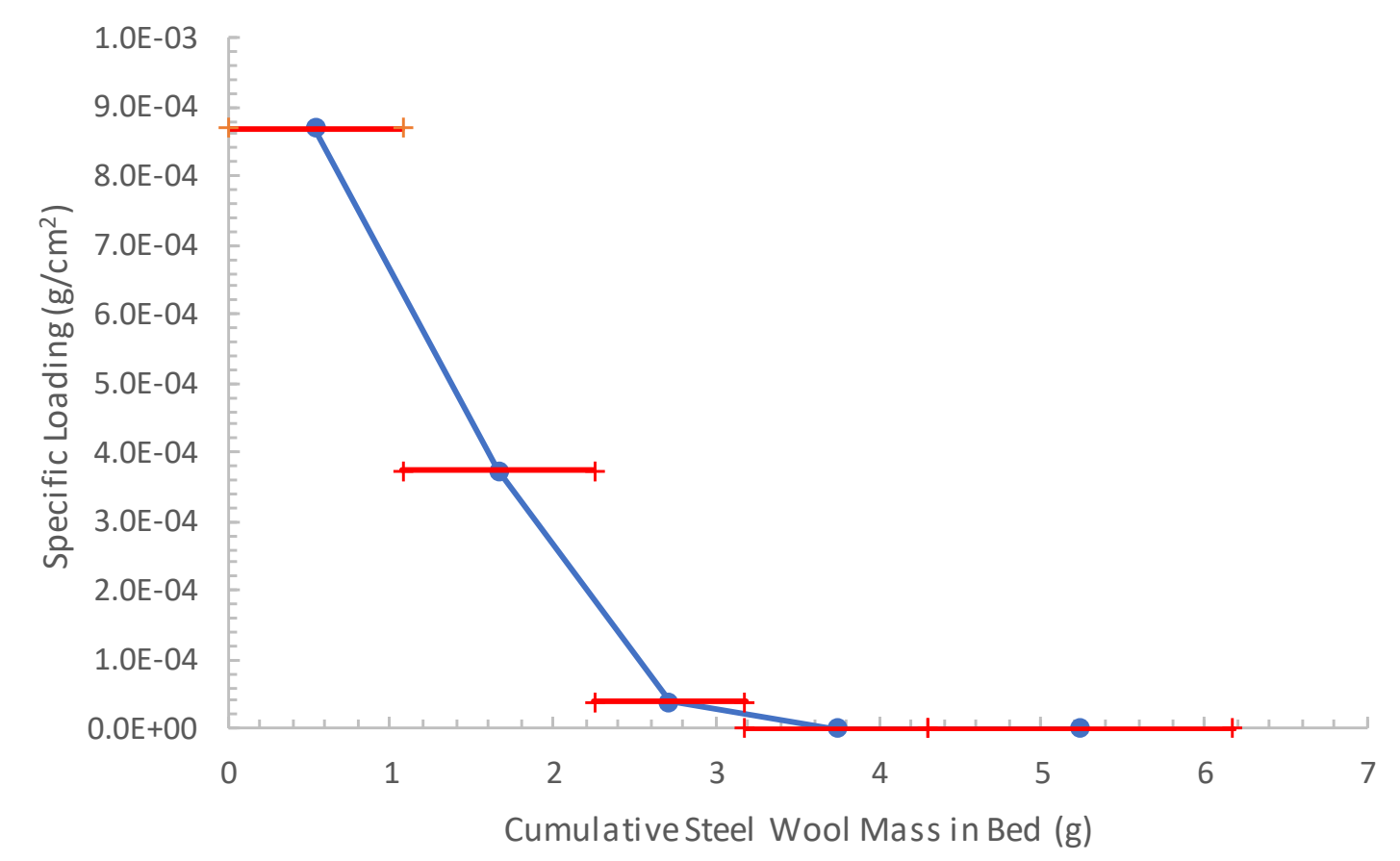

Figure 22. Specific ruthenium loading as a function of cumulative mass of steel wool in the bed. Points are placed at the mid-point of the mass of each wool section.

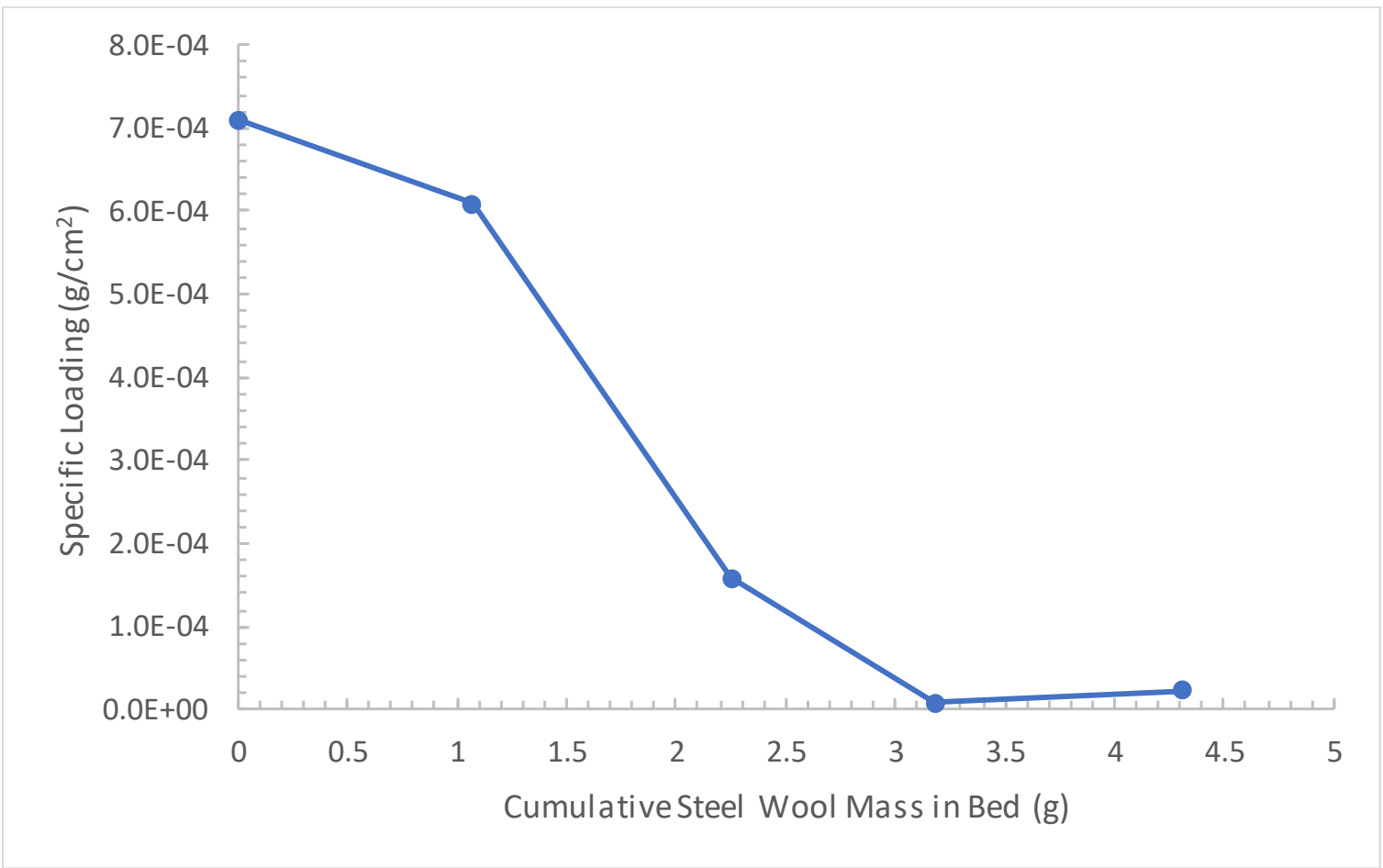

Figure 23. Specific ruthenium loading on mesh screens as a function of the cumulative mass of steel wool preceding the mesh. 
temperature. The curves of Figures 22 and 23 are combined in Figure 24 to better compare the specific loading through the sorbent.

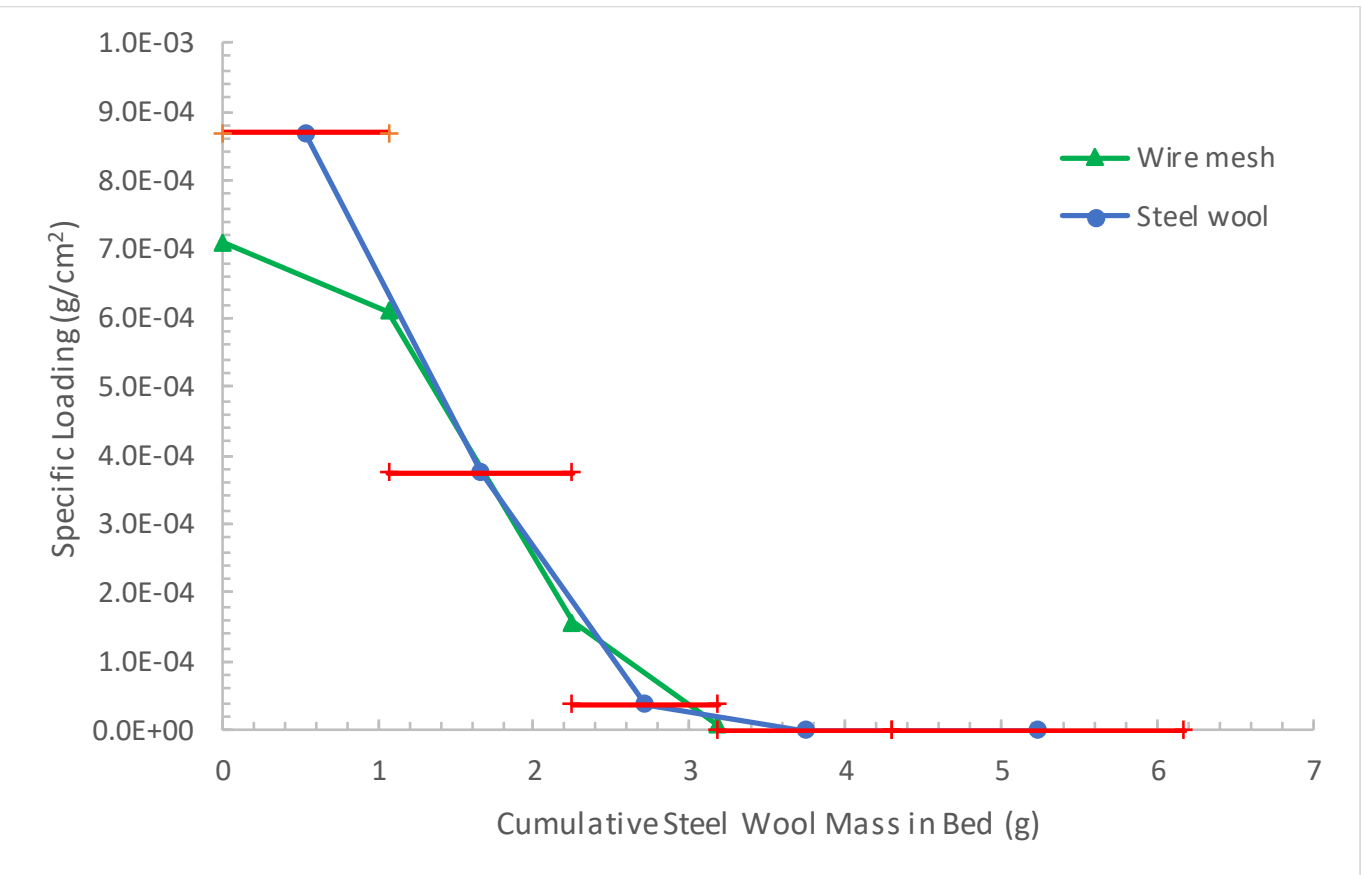

Figure 24. Comparison of specific ruthenium loading on the screen mesh and the steel wool as a function of cumulative mass of wool in the bed.

Run 13 repeated the conditions of Run 12 , except the sorbent was maintained at $250^{\circ} \mathrm{C}$ instead of $150^{\circ} \mathrm{C}$. At the end of the run, it was observed that black deposits were on the quartz tube $4-5$ in. upstream of the packing. At the higher temperature, the tube column was evidently heated sufficiently by conduction to cause deposition. This necessarily reduces the $\mathrm{RuO}_{4}$ reaching the packing. As shown in Table 7, only the first screen and first steel wool section significantly gained weight. Figure 25 shows the first screen and first steel wool section. The screen was scratched and flexed during removal from the quartz column, causing some loss of the deposit, so the deposition loading was higher than indicated in Table 7. Loading on the screen was very high at $28.3 \mathrm{wt} \%$, and on the steel wool it was $15.3 \mathrm{wt} \%$. The specific loading on the screen was $6.5 \times 10^{-3} \mathrm{~g} / \mathrm{cm}^{2}$, and the specific loading on the steel wool was $6.4 \times 10^{-4} \mathrm{~g} / \mathrm{cm}^{2}$, an order of magnitude variation that could be indicative of depletion of $\mathrm{RuO}_{4}$ from the gas stream. Based on the specific loading on the screen and the density of $\mathrm{RuO}_{2}\left(6.97 \mathrm{~g} / \mathrm{cm}^{3}\right)$, the calculated thickness of the deposit is $9.3 \mu \mathrm{m}$ (which is likely somewhat low because of the aforementioned scratches). The SEM image of the coating where there is a chipped section, shown in Figure 26, indicates that the deposited $\mathrm{RuO}_{2}$ layer was as thick as $15 \mu \mathrm{m}$. Because only the first section of steel wool gained weight, penetration of $\mathrm{RuO}_{4}$ into the sorbent bed was only $\sim 0.63$ in. 

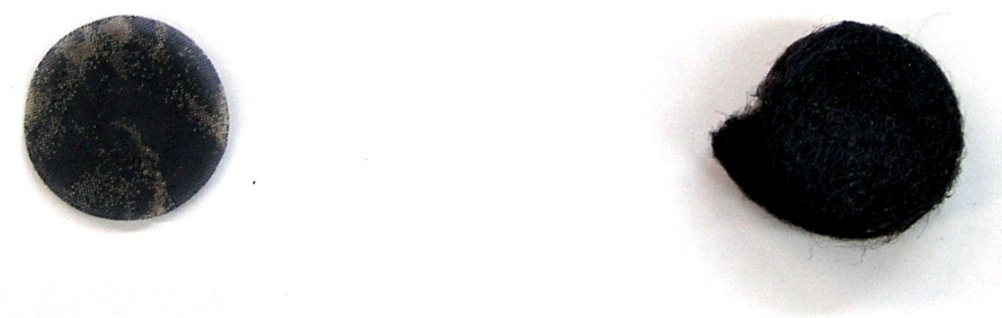

Figure 25. First screen (RO-13-01) and steel wool section (RO-13-01w) recovered following Run 13.

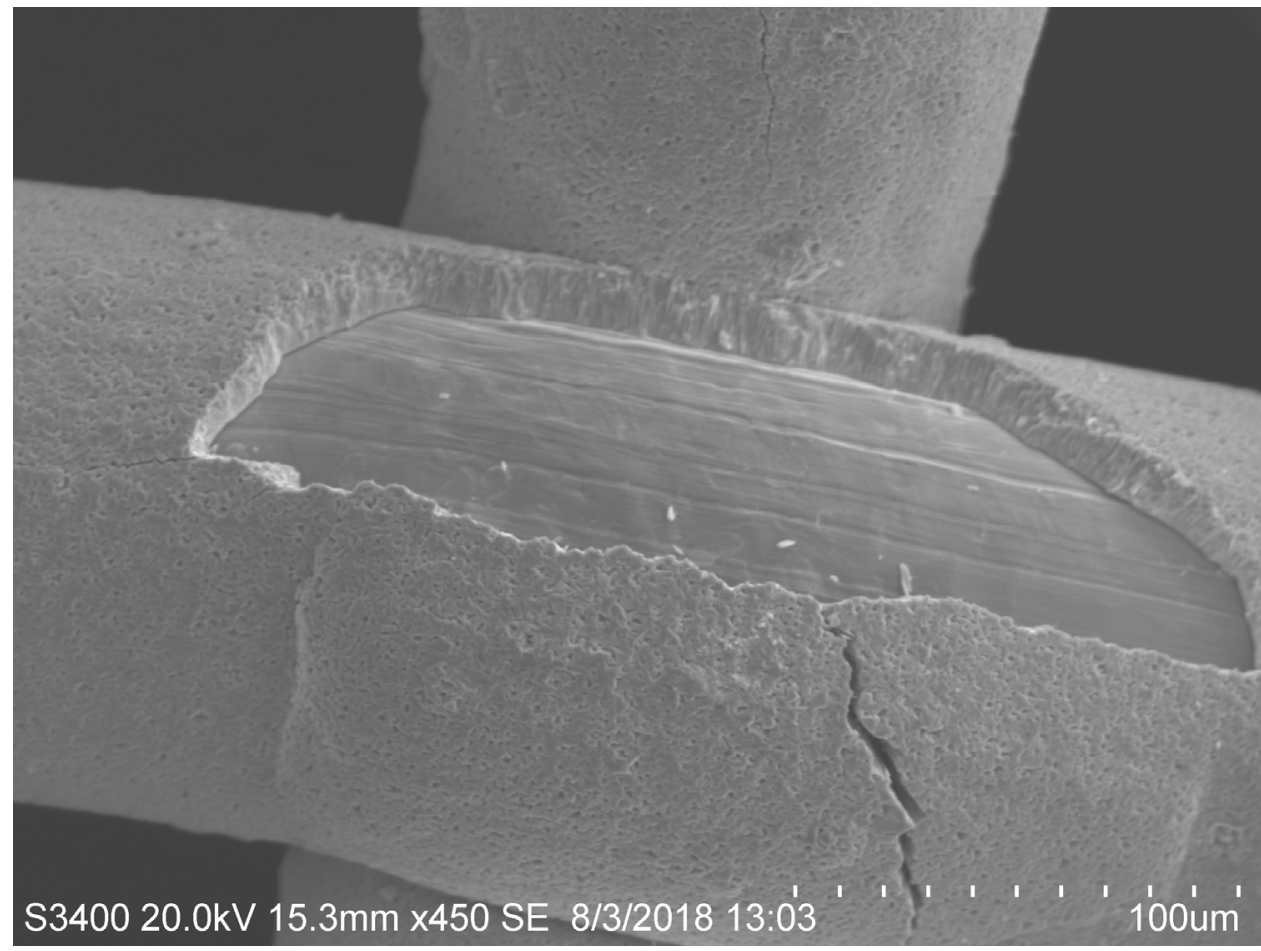

Figure 26. SEM image of screen RO-13-01 from Run 13. The area where the coating is chipped from the surface reveals the depth of the $\mathrm{RuO}_{2}$ deposit. 


\subsection{Estimated Decontamination Factors}

Selected scrubber solutions were analyzed by inductively coupled plasma-mass spectroscopy (ICP-MS) to determine the quantity of ruthenium that passed through the sorbent bed. Results are shown in Table 8 . Runs 7 and 8 were conducted using oxidation of ruthenium metal with pure oxygen to produce $\mathrm{RuO}_{4}$. In Run 7 there was no sorbent, and in Run 8 the primary sorbent was stainless steel wire screen (although the spacers between the screens also showed deposits). In both cases, most of the generated $\mathrm{RuO}_{4}$ was expected to report to the scrubber. As shown in Table 8, the concentrations of ruthenium in the scrubber solution were in the $1-2 \mu \mathrm{m} / \mathrm{mL}$ range, indicating about $1 \mathrm{mg}$ of ruthenium (metal equivalent) reached the scrubber. This corroborated the suspicion that oxidation of ruthenium metal powder produced little $\mathrm{RuO}_{4}$.

Runs 10-13 were conducted using oxidation of $\mathrm{RuO}_{2}$ with $\mathrm{NaIO}_{4}$ in aqueous solution to produce $\mathrm{RuO}_{4}$. As shown in Section 4.3, weight gain of the sorbent material indicated that a large fraction of the $\mathrm{RuO}_{2}$ charged to the generator was converted to $\mathrm{RuO}_{4}$. The low concentrations of ruthenium in the scrubber solutions, shown in Table 8, indicate that the high surface area sorbent (steel wool) was effective in trapping the ruthenium.

Table 8. Analysis of scrubber solution for selected experiments and calculated mass of ruthenium retained in solution.

\begin{tabular}{|l|c|c|c|c|}
\hline \multicolumn{1}{|c|}{ Sample no. } & $\begin{array}{c}\text { Ru concn. } \\
(\mu \mathrm{g} / \mathrm{mL})^{\mathrm{a}}\end{array}$ & $\begin{array}{c}\text { Ru concn. } \\
\text { uncertainty } \\
(\%)\end{array}$ & $\begin{array}{c}\text { Volume } \\
(\mathrm{mL})\end{array}$ & $\begin{array}{c}\text { Total Ru in scrub } \\
\text { solution } \\
(\mathrm{g})\end{array}$ \\
\hline RO-7-Bu & $2.00 \mathrm{E}+00$ & 10 & 550 & $1.10 \mathrm{E}-03$ \\
\hline $\mathrm{RO}-8-\mathrm{Bu}$ & $9.73 \mathrm{E}-01$ & 10 & 450 & $4.38 \mathrm{E}-04$ \\
\hline $\mathrm{RO}-10-\mathrm{Bu}$ & $2.48 \mathrm{E}+00$ & 10 & 432 & $1.07 \mathrm{E}-03$ \\
\hline $\mathrm{RO}-11-\mathrm{Bu}$ & $<8.51 \mathrm{E}-04$ & N/A & 432 & $<3.68 \mathrm{E}-07$ \\
\hline RO-12-Bu & $<4.25 \mathrm{E}-04$ & N/A & 400 & $<1.70 \mathrm{E}-07$ \\
\hline RO-13-Bu & $1.84 \mathrm{E}-03$ & 20 & 400 & $7.32 \mathrm{E}-07$ \\
\hline
\end{tabular}

${ }^{a}$ Values with $<$ symbol are the limit of detection, and no ruthenium was detected.

Table 9 summarizes the results of calculations to estimate the quantities of ruthenium converted to $\mathrm{RuO}_{4}$, which was transported to the sorption bed; the values were converted to the equivalent mass of $\mathrm{RuO}_{2}$ because that was the expected form deposited on the sorbents. In Runs 7-8, the $\mathrm{RuO}_{4}$ generator was charged with a weighed amount of Ru metal powder, and at the end of the run the powder was reweighed. The mass of the metal charged increased. Under the assumption that all metal was converted to $\mathrm{RuO}_{2}$, the difference in weight between that calculated from the mass of metal and the actual weight of recovered $\mathrm{RuO}_{2}$ was the mass of $\mathrm{RuO}_{2}$ volatilized by conversion to $\mathrm{RuO}_{4}$ - in Table 9 it is labeled the amount of $\mathrm{RuO}_{2}$ consumed in the generator. It was thought very likely that not all the ruthenium metal powder would oxidize, thus the amount calculated by the above difference would be the upper limit of $\mathrm{RuO}_{2}$ (equivalent) volatilized. The ratio of the mass of $\mathrm{RuO}_{2}$ consumed to the mass of $\mathrm{RuO}_{2}$ (equivalent) found in the scrubber solution estimates the decontamination factor (DF). As shown in Table 9, the DFs are under 200 and are probably very much smaller than that because of the assumptions used concerning the oxidation of the ruthenium metal.

In Runs 10-13, the method to generate $\mathrm{RuO}_{4}$ converted all the $\mathrm{RuO}_{2}$ in the charge. The manufacturer's data on the $\mathrm{RuO}_{2}$ showed that the oxide was hydrated and that the ruthenium (metal equivalent) of the material was $\geq 54 \mathrm{wt} \%$. Using $54 \%$ of the mass of the $\mathrm{RuO}_{2}$ shown in Table 9 as the amount of ruthenium 
metal, the calculated amount of $\mathrm{RuO}_{2}$ converted to $\mathrm{RuO}_{4}$ would be smaller than the actual amount volatilized (i.e., the amount volatilized and transported to the sorbent bed would be greater than the calculated amount). Both the calculated amount and any value of the quantity of $\mathrm{RuO}_{2}$ in the scrub solution below detection limits means that the actual DF will be greater than the value calculated. Results are shown in Table 9. In Run 10 the steel wool was not tightly packed (as previously described) and approximately $1 \mathrm{mg}$ of ruthenium reached the scrubber (enough to cause a color change in the solution). As shown, the estimated DF was $>273$. In Runs 11-12 the ruthenium concentration was below the detectable limit of just under $1 \mathrm{ng} / \mathrm{mL}$. Consequently, the estimated DFs were $>10^{6}$. In Run 13, the sorbent was held at the highest temperature of $250^{\circ} \mathrm{C}$, and the penetration of ruthenium into the bed was very short. Nonetheless, the ruthenium found in the scrubber solution was just above the detection limit, and the estimated DF was $>3 \times 10^{5}$. Overall, heated high-surface-area metal sorbents (or deposition surfaces) are very effective at removing $\mathrm{RuO}_{4}$ from gas streams, and the DFs are very high.

Table 9. Estimated DFs describing removal of removal of ruthenium from a gas.

\begin{tabular}{|l|c|c|c|l|}
\hline Run no. & $\begin{array}{c}\mathrm{RuO}_{2} \text { consumed } \\
\text { in the generator } \\
(\mathrm{g})\end{array}$ & $\begin{array}{c}\mathrm{RuO}_{2} \text { in scrub }^{\mathrm{b}} \\
(\mathrm{g})\end{array}$ & $\begin{array}{c}\text { Decontamination } \\
\text { factor } \\
(\mathrm{DF})^{\mathrm{e}}\end{array}$ & \multicolumn{1}{|c|}{$\begin{array}{c}\text { Identification of } \\
\text { sorbing surfaces } \\
\text { (quartz tube omni-present })\end{array}$} \\
\hline RO-7 & $<0.1053^{\mathrm{c}}$ & $1.45 \mathrm{E}-03$ & $<72.7$ & $\begin{array}{l}\text { No sorbent bed, some } \\
\text { deposits on generator tube }\end{array}$ \\
\hline RO-8 & $<0.1046^{\mathrm{c}}$ & $5.77 \mathrm{E}-04$ & $<181.0$ & $\begin{array}{l}\text { Stainless steel mesh, glass, } \\
\text { and Teflon spacers }\end{array}$ \\
\hline RO-10 & $0.5426^{\mathrm{d}}$ & $1.41 \mathrm{E}-03$ & $>273.0$ & $\begin{array}{l}\text { Stainless steel mesh, steel } \\
\text { wool }\end{array}$ \\
\hline RO-11 & $2.5768^{\mathrm{d}}$ & $<4.85 \mathrm{E}-07$ & $>3.78 \mathrm{E}+06$ & $\begin{array}{l}\text { Stainless steel mesh, steel } \\
\text { wool }\end{array}$ \\
\hline RO-12 & $0.5153^{\mathrm{d}}$ & $<2.24 \mathrm{E}-07$ & $>1.63 \mathrm{E}+06$ & $\begin{array}{l}\text { Stainless steel mesh, steel } \\
\text { wool }\end{array}$ \\
\hline RO-13 & $0.5023^{\mathrm{d}}$ & $9.64 \mathrm{E}-07$ & $>3.70 \mathrm{E}+05$ & $\begin{array}{l}\text { Stainless steel mesh, steel } \\
\text { wool }\end{array}$ \\
\hline
\end{tabular}

${ }^{a}$ Basis for amount of ruthenium volatilized (presumably as $\mathrm{RuO}_{4}$ ) and carried by the gas stream to the sorbent column.

${ }^{\mathrm{b}}$ Calculated from amount of ruthenium found in scrubber solution by ICP-MS (Ru quantity found in Table 8).

${ }^{c}$ Value calculated assuming all ruthenium metal powder in the charge was oxidized to $\mathrm{RuO}_{2}$, subtracting the measured mass of $\mathrm{RuO}_{2}$ remaining in the generator.

${ }^{d}$ This oxide may have been partially hydrated; manufacturer data indicate ruthenium content $\geq 54 \mathrm{wt} \%$, so the $\mathrm{RuO}_{2}$ in the compound was taken as $\geq 71 \%$ of the mass to calculate DF on the basis of dry $\mathrm{RuO}_{2}$ mass.

${ }^{\mathrm{e}} \mathrm{DF}$ is calculated as the ratio of the mass of volatilized ruthenium transported to the sorbent bed to the mass of ruthenium leaving sorbent bed. It assumes all ruthenium leaving sorbent bed is captured in the scrubber.

\section{CONCLUSIONS AND RECOMMENDATIONS}

\subsection{Conclusions}

Tests were conducted to measure the deposition of ruthenium on metal sorbent surfaces. In the initial experiments, oxidation of powdered ruthenium metal to prepare a dry gas stream containing $\mathrm{RuO}_{4}$ did not produce sufficient $\mathrm{RuO}_{4}$ to permit tests to be conducted in reasonable durations (i.e., streams were very lean in $\mathrm{RuO}_{4}$ and a long time would be required to load the sorbent). Oxidation of $\mathrm{RuO}_{2}$ in molten $\mathrm{NaIO}_{4}$ 
appeared to produce usable amounts of $\mathrm{RuO}_{4}$, but iodine was also released into the carrier gas stream. In addition, there was a tendency for the $\mathrm{RuO}_{4}$ to deposit on the hot surfaces of the generator immediately downstream from the melt. Oxidation of $\mathrm{RuO}_{4}$ in an aqueous solution of $\mathrm{NaIO}_{4}$ was the simplest and most reliable technique. Bubbling a carrier gas through the solution resulted in transfer of the $\mathrm{RuO}_{4}$ from the aqueous phase to the gas phase. Although deposition occurred on the room temperature transfer tubing, it was very minimal, and most of the volatile ruthenium reported to the adsorption column, aqueous scrubber, or both. Because little change was observed in the volume of the solution in the $\mathrm{RuO}_{4}$ generator, the amount of water vapor transferred to the carrier gas stream was evidently small. Some interesting highlights of the sorption tests are:

- Penetration of the sorbate into the steel wool varies strongly with the packing density of the wool, ranging from 1.5 to 6 in. (3.81 to $15.2 \mathrm{~cm}$ ) with linear packing density ranging from 0.39 to $0.64 \mathrm{~g} / \mathrm{cm}$, respectively, at $0.25 \mathrm{slpm}$ gas flow and a sorbent bed temperature of $150^{\circ} \mathrm{C}$. The increased packing density of the steel wool increases the deposition surface area per unit length of column and decreases the mass transfer distance between the bulk gas phase and the surface.

- Penetration decreased to under $\sim 1$ in. $(2.5 \mathrm{~cm})$ with an increase in temperature to $250^{\circ} \mathrm{C}$.

- The specific loading, defined as grams per square centimeter of surface area, of both the screens and steel wool are numerically similar.

- It appears that the deposits continue to build up, growing thicker as deposition continues. The mass transfer zone does not appear to move along the bed like it does in the chemisorption or physisorption processes.

- The ruthenium appears to deposit on any warm surface it encounters, be it quartz, glass, metal, or even polymer. It deposits at much slower rate on cooler surfaces, such as portions of the quartz column that protrude from the front of the oven.

- When the deposit layer becomes thick enough, thermal cycling seems to cause it to flake from the surface of the quartz column. Bending of the wire mesh screens also caused the deposit to flake off.

- Analysis of the scrubber solutions permitted estimation of the amount of ruthenium passing the sorbent beds. Comparing this amount to the amount of volatile ruthenium transferred to the sorbent beds lead to estimated DFs in excess of $10^{6}$ for sorbent beds composed of steel wool.

\subsection{Implications for Ruthenium Capture Systems and Recommendations}

It is known that ${ }^{106} \mathrm{Ru}$ is the only remaining radioisotope of ruthenium remaining in used fuel cooled at least five years, and that it is intensely radioactive because of the short half-life (372.6 days). The mass of all ruthenium isotopes is about $2-3 \mathrm{~kg}$ per metric ton of used fuel (heavy metal basis) and ${ }^{106} \mathrm{Ru}$ is a tiny fraction (on the order of $\sim 10^{-12} \mathrm{~g} / \mathrm{g}$ ) of the total. A few considerations and recommendations for design of ruthenium capture systems and disposal of the captured ruthenium are:

- Deposits could build up until the sorbent material plugs. As the channels become more and more constricted (i.e., as surface area is lost), there should be a tendency for deposits to occur deeper in the bed, but the pressure drop could become high enough that, for practical purposes, the bed is plugged. For a proposed design, pressure differential should be evaluated as one potential means to infer loading during operation.

- The penetration of ruthenium into the bed depends strongly on the temperature of the deposition surface. Self-heating caused by decay of ${ }^{106} \mathrm{Ru}$ should be considered. Designs should consider that operating temperatures in excess of $150^{\circ} \mathrm{C}$ could collect ruthenium in a short section of the bed and 
may result in localized over-heating. Operation at lower temperatures may increase the penetration depth, spreading the heat-load. The area of deposition surface per unit length of the sorbent bed will also be a design variable. These are some of the factors to be considered in design of an appropriate sorbent bed.

- In the initial scoping tests (Spencer et al. 2018), the $\mathrm{RuO}_{4}$ deposited on silica gel at a temperature of $40^{\circ} \mathrm{C}$ was found to desorb while sitting at room temperature for 1-2 days. The present data suggest that deposition at higher temperatures would have prevented the desorption because of the decomposition of $\mathrm{RuO}_{4}$ to $\mathrm{RuO}_{2}$. However, it is doubtful that there is any advantage to silica gel because the microchannels will likely plug or become occluded rather rapidly, preventing penetration of $\mathrm{RuO}_{4}$ deep into the pellet structure. The present data indicate that metal surfaces are rather uniformly coated and are preferred.

- The waste form does not seem to require conversion to a form that is stable over geologic time frames. The half-life of ${ }^{106} \mathrm{Ru}$ is 372.6 days (1.02 yrs), decaying to very short-lived rhodium, which decays to stable palladium. A deposition bed contained in a robust steel column could be sealed (e.g., by welding) and used as the storage and disposal container. Design of the column/storage container should consider the cooling requirements (e.g., natural draft cooling) until the ${ }^{106} \mathrm{Ru}$ has decayed sufficiently for ultimate disposition. Long-term stability of the waste may become an issue if longlived species are co-deposited with the ruthenium. Such a potential should be further investigated. 


\section{REFERENCES}

Jubin, R. T., D. M. Strachan, G. Ilas, B. B. Spencer, and N. R. Soelberg. 2014. Radioactive Semivolatiles in Nuclear Fuel Reprocessing, Report No. FCRD-SWF-2014-000601 (ORNL/LTR-2014/354), Oak Ridge National Laboratory, Oak Ridge, TN, September 12.

Jubin, R. T., S. H. Bruffey, B. B. Spencer, and D. M. Strachan. 2017. Evaluation of Ruthenium Capture Methods for Tritium Pretreatment Off-Gas Streams, Report No. NTRD-MRWFD-2017-000312, ORNL/TM-2017/330, Oak Ridge National Laboratory, Oak Ridge, TN, June 30.

Lee, D. G., D. T. Hall, and J. H. Cleland. 1972. "The Oxidation of Organic Compounds by Sodium Ruthenate," Canadian Journal of Chemistry, vol. 50, pp. 3741-3743.

McMaster-Carr catalog. 2018. "Stainless Steel Wire Cloth,” https://www.mcmaster.com/\#wirecloth/=1du68fq, accessed February 1, 2018.

Palmer Engineering. 2018. "Standard Steel Wool Specifications," http://www.palmereng.com/moreinfo/wool_standard_steel_wool_specs.htm, accessed June 15, 2018. Perry, R. H. and C. H. Chilton. 1973. Chemical Engineer's Handbook, 5th ed., New York: McGraw-Hill. Spencer, B. B., M. L. Parks, and S. H. Bruffey. 2018. Initial Assessment of Ruthenium Removal Systems for Tritium Pretreatment Off-Gas, Report No. NTRD-MRWFD-2018-000200, ORNL/SPR-2017/576, Oak Ridge National Laboratory, Oak Ridge, TN, January 31. 